\title{
Unsteady Flow of Reactive Viscous, Heat Generating/Absorbing Fluid with Soret and Variable Thermal Conductivity
}

\author{
I. J. Uwanta and M. M. Hamza \\ Department of Mathematics, Usmanu Danfodiyo University, PMB 2346, Sokoto, Nigeria \\ Correspondence should be addressed to M. M. Hamza; hmbtamb@yahoo.com
}

Received 14 February 2014; Revised 31 May 2014; Accepted 26 June 2014; Published 23 July 2014

Academic Editor: Doraiswami Ramkrishna

Copyright ( 2014 I. J. Uwanta and M. M. Hamza. This is an open access article distributed under the Creative Commons Attribution License, which permits unrestricted use, distribution, and reproduction in any medium, provided the original work is properly cited.

\begin{abstract}
This study investigates the unsteady natural convection and mass transfer flow of viscous reactive, heat generating/absorbing fluid in a vertical channel formed by two infinite parallel porous plates having temperature dependent thermal conductivity. The motion of the fluid is induced due to natural convection caused by the reactive property as well as the heat generating/absorbing nature of the fluid. The solutions for unsteady state temperature, concentration, and velocity fields are obtained using semi-implicit finite difference schemes. Perturbation techniques are used to get steady state expressions of velocity, concentration, temperature, skin friction, Nusselt number, and Sherwood number. The effects of various flow parameters such as suction/injection $(\gamma)$, heat source/sinks $(S)$, Soret number $(\mathrm{Sr})$, variable thermal conductivity $(\delta)$, Frank-Kamenetskii parameter $(\lambda)$, Prandtl number $(\operatorname{Pr})$, and nondimensional time $(t)$ on the dynamics are analyzed. The skin friction, heat transfer coefficients, and Sherwood number are graphically presented for a range of values of the said parameters.
\end{abstract}

\section{Introduction}

Natural convection flow in a porous channel in the presence of chemical reaction is important in the design of several equipment used in engineering systems, for instance in the design of nuclear reactors, thermal insulation, surface catalysis of chemical reaction, small domestic mobile winter oil heaters, and some types of radiators and hydronic heating systems. In chemical engineering and petroleum chemical industries, the interaction between chemical reaction and natural convection occurs widely. Examples of such area of applications include tubular laboratory reactors, chemical vapor deposition systems, the oxidation of solid materials in large containers, the synthesis of ceramic materials by a selfpropagating reaction, combustion in underground reservoirs for enhanced oil recovery, and the reduction of hazardous combustion product using catalytic porous beds and many others. In an attempt to study the effect of chemical reaction on natural convection flows, Minto et al. [1] studied natural convection flow driven by an exothermic reaction on a vertical surface embedded in porous media. Campbell et al. [2] reported the comparison of measured temperatures with those calculated numerically and analytically for an exothermic chemical reaction inside a spherical batch reactor with natural convection. They concluded that the transport of heat and mass transfer within the reactor is controlled by diffusion or natural convection. Recently, Jha et al. [3$6]$ investigated unsteady natural convection flow of reactive viscous fluid in a vertical channel as well as vertical tube and the reaction is exothermic under Arrhenius kinetics, neglecting the consumption of the materials. On the other hand the study of heat generation/absorption effects is also important in view of several physical problems, such as fluids undergoing endothermic or exothermic chemical reactions. Heat generation/absorption plays significant role in various physical phenomena such as convection in earth's mantle, postaccident removal, fire and combustion modelling, and the development of metal waste from nuclear fuel (Jha and Ajibade [7]). Vajravelu [8] investigated heat source/sink effect on natural convection past an infinite vertical plate. Crepeau 
and Clarksean [9] presented similarity solutions of natural convection flow with internal heat generation. All the features for heat generating/absorbing fluids have been reported by Jha and Ajibade [7] in their studies on the free convective flow between vertical porous plates with periodic input.

Combined heat and mass transfer problems on natural convection flow found applications in natural circulation in geothermal reservoir, packed bed reactors, sensible heat storage beds, and beds of fossil fuels such as oil shale and coal which have been fragmented in situ energy extraction (Postelnicu [10]). Mass fluxes can also be generated by temperature gradients. These fluxes generated by temperature gradients are called Soret effect or thermal diffusion. Soret effect is important where more than one chemical species are present under a very large temperature gradient, such as chemical reactors and isotope separation and in mixture between gases of very light molecular weight, such as hydrogen or helium, and of medium molecular weight, such as nitrogen or air $[10,11]$. Due to the applications of Soret effect in fluids with very light molecular weight as well as medium molecular weight many researchers across the globe have investigated Soret effect whose names are Dursunkaya and Worek [12], Osalusi et al. [13], and Tsai and Huang [14]. Recently Turkyilmazoglu and Pop [15] studied the effect of Soret and heat source on the unsteady radiative MHD free convection flow from an impulsively infinite vertical plate.

To accurately predict the flow and heat transfer rate, it is necessary to take into account the variation of thermal conductivity and viscosity [16]. The materials properties such as thermal conductivity are likely to vary with a temperature gradient [17]. Also thermal conductivity plays a role in controlling heat transfer and temperature increases in the vicinity of repository. In this direction, Arunachalam and Rajappa [18] reported forced convection in liquid metal with variable thermal conductivity. Chiam $[19,20]$ investigated the effect of variable thermal conductivity on heat transfer. Abel et al. [21] studied numerically the effects of variable thermal conductivity on MHD flow in a power-law fluid past a vertical stretching sheet in the presence of nonuniform heat source. Seddeek and Salama [22] presented numerically the effects of variable viscosity and variable thermal conductivity on unsteady MHD convective heat transfer in a vertical moving porous plate with variable suction. Suction or injection of a fluid through the bounding surface as for example in mass transfer cooling can significantly change the flow field and as a result affect the heat transfer rate from the plate (Ishak et al. [23]). Suction/injection found applications in the field of aerodynamics and space science (Singh [24]). Shojaefard et al. [25] used suction and injection to control fluid flow on the surface of subsonic aircraft.

The purpose of this paper is to analyze both analytically and numerically the effects of suction/injection, heat generating/absorbing, Soret number, Frank-Kamenetskii parameter, and variable thermal conductivity on unsteady natural convection and mass transfer flow with an exothermic chemical reaction between two infinite vertical porous plates with variable thermal conductivity.

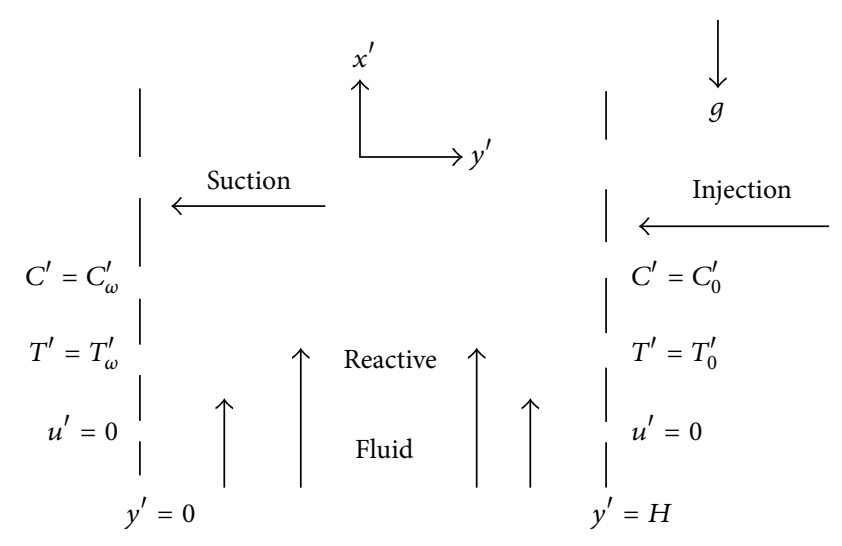

FIGURE 1: Geometry of the problem.

\section{Mathematical Analysis}

Consider the unsteady natural convection and mass transfer flow of viscous reactive, heat generating/absorbing fluid between infinite vertical parallel porous plates, having temperature dependent thermal conductivity. The convective current is a result of the reactive property of the fluid as well as heat generating/absorbing nature of the fluid. At time $t^{\prime} \leq 0$, both the fluid and the plates are at rest and at the same temperature and concentration $T_{0}^{\prime}$ and $C_{0}^{\prime}$, respectively. At time $t^{\prime}>0$ the temperature and concentration of the plate $y^{\prime}=0$ raised to $T_{\omega}^{\prime}$ and $C_{\omega}^{\prime}$, and those of $y^{\prime}=H$ are lowered to $T_{0}^{\prime}$ and $C_{0}^{\prime}$, respectively, where $T_{\omega}^{\prime}>T_{0}^{\prime}$ and $C_{\omega}^{\prime}>C_{0}^{\prime}$. It is assumed that the fluid is injected into the channel wall at $y^{\prime}=H$ with velocity $v^{\prime}=-v_{0}$ and that it is sucked off by the other channel wall at $y^{\prime}=0$ the same rate (see Figure 1). The heat generating/absorbing term in this problem is assumed to be of a type given by [26]. The fluid in the present configuration is incompressible and the physical properties are assumed to be constant excluding density in the buoyancy term. Following Jha et al. [3-5] and neglecting the reacting viscous fluid consumption, the governing equations under the Boussinesq's approximation can be written as

$$
\begin{aligned}
\frac{\partial u^{\prime}}{\partial t^{\prime}}-v_{0} \frac{\partial u^{\prime}}{\partial y^{\prime}}= & v \frac{\partial^{2} u^{\prime}}{\partial y^{\prime 2}}+g \beta\left(T^{\prime}-T_{0}^{\prime}\right)+g \beta^{*}\left(C^{\prime}-C_{0}^{\prime}\right) \\
\frac{\partial C^{\prime}}{\partial t^{\prime}}-v_{0} \frac{\partial C^{\prime}}{\partial y^{\prime}}= & D_{m} \frac{\partial^{2} C^{\prime}}{\partial y^{\prime 2}}+\frac{D_{m} k_{T}}{T_{m}} \frac{\partial^{2} T^{\prime}}{\partial y^{\prime 2}} \\
\frac{\partial T^{\prime}}{\partial t^{\prime}}-v_{0} \frac{\partial T^{\prime}}{\partial y^{\prime}}= & \frac{1}{\rho C_{p}} \frac{\partial}{\partial y^{\prime}}\left[K_{f}(T) \frac{\partial T^{\prime}}{\partial y^{\prime}}\right]+\frac{Q C_{0}^{*} A}{\rho C_{p}} e^{\left(-E / R T^{\prime}\right)} \\
& +\frac{Q_{0}\left(T^{\prime}-T_{0}\right)}{\rho C_{p}} .
\end{aligned}
$$

The initial and boundary conditions for the present problem are

$$
t^{\prime} \leq 0: u^{\prime}=0, \quad T^{\prime} \longrightarrow T_{0}^{\prime}, \quad C^{\prime} \longrightarrow C_{0}^{\prime}, \quad 0 \leq y^{\prime} \leq H,
$$




$$
\begin{aligned}
t^{\prime}>0: u^{\prime}=0, \quad T^{\prime}=T_{\omega}^{\prime}, \quad C^{\prime}=C_{\omega}^{\prime} \quad \text { at } y^{\prime}=0, \\
u^{\prime}=0, \quad T^{\prime}=T_{0}^{\prime}, \quad C^{\prime}=C_{0}^{\prime} \quad \text { as } y^{\prime} \longrightarrow H,
\end{aligned}
$$

where $\beta$ is the coefficient of thermal expansion, $\beta^{*}$ is the coefficient of concentration expansion, $Q$ is the heat of reaction, $Q_{0}$ is the dimensional heat generating/absorbing parameter, $A$ is the rate constant, $E$ is the activation energy, $R$ is the universal gas constant, $v$ is the kinematic viscosity, $C_{0}^{*}$ is the initial concentration of the reactant species, $g$ is the gravitational force, $C_{p}$ is the specific heat at constant pressure, $\rho$ is the density of the fluid, $D_{m}$ is the coefficient of mass diffusivity, $T_{m}$ is the mean fluid temperature, $k_{T}$ is the thermal diffusion ratio, and $K_{f}(T)$ is the thermal conductivity which is assumed to vary as linear function of temperature in the form [16, 21], $K_{f}(T)=K_{0}\left\{1+m^{*}\left(T^{\prime}-T_{0}^{\prime}\right)\right\}$, where $K_{0}$ is the thermal conductivity of the ambient fluid and $m^{*}$ is a constant depending on the nature of the fluid. In general, $m^{*}>0$ for fluids such as water and air, while $m^{*}<0$ for fluids such as lubrication oils [16].

In the above equations and the initial and boundary conditions, we introduce the following nondimensional variables and parameters:

$$
\begin{aligned}
& y=\frac{y^{\prime}}{H}, \quad t=\frac{t^{\prime} v}{H^{2}}, \quad u=\frac{u^{\prime}}{v_{0}}, \\
& \operatorname{Pr}=\frac{\nu \rho C_{p}}{k}, \quad \mathrm{Gc}=\frac{g \beta^{*} R C_{0}^{2} H^{2}}{E \nu \nu_{0}} \\
& \theta=\frac{E\left(T^{\prime}-T_{0}\right)}{R T_{0}^{2}}, \quad \lambda=\frac{Q C_{0} A E H^{2}}{R T_{0}^{2}} e^{\left(-E / R T_{0}\right)}, \\
& \mathrm{Sc}=\frac{v}{D_{m}}, \quad \mathrm{Sr}=\frac{k_{T} T_{0}^{2}}{T_{m} C_{0}^{2}} \\
& \varepsilon=\frac{R T_{0}}{E}, \quad \theta_{T}=\frac{E\left(T_{\omega}-T_{0}\right)}{R T_{0}^{2}}, \\
& S=\frac{Q_{0} H^{2}}{k}, \quad \gamma=\frac{v_{0} H}{v}, \quad C_{T}=\frac{E\left(C_{\omega}-C_{0}\right)}{R C_{0}^{2}} \\
& \mathrm{Gr}=\frac{g \beta R T_{0}^{2} H^{2}}{E \nu \nu_{0}}, \quad \delta=\frac{m^{*} R T_{0}^{2}}{E}, \quad C=\frac{E\left(C^{\prime}-C_{0}\right)}{R C_{0}^{2}}
\end{aligned}
$$

Using (3), (1) to (2) can take the following form:

$$
\begin{aligned}
& \frac{\partial u}{\partial t}-\gamma \frac{\partial u}{\partial y}=\frac{\partial^{2} u}{\partial y^{2}}+\mathrm{Gr} \theta+\mathrm{GcC}, \\
& \mathrm{Sc}\left(\frac{\partial C}{\partial t}-\gamma \frac{\partial C}{\partial y}\right)=\frac{\partial^{2} C}{\partial y^{2}}+\operatorname{Sr} \frac{\partial^{2} \theta}{\partial y^{2}}, \\
& \operatorname{Pr}\left(\frac{\partial \theta}{\partial t}-\gamma \frac{\partial \theta}{\partial y}\right)=(1+\delta \theta) \frac{\partial^{2} \theta}{\partial y^{2}}+\delta\left[\frac{\partial \theta}{\partial y}\right]^{2} \\
& +\lambda e^{(\theta /(1+\varepsilon \theta))}+S \theta \\
& u=0, \quad \theta=0, \quad 0 \leq y \leq 1, \quad t \leq 0
\end{aligned}
$$

$$
\begin{array}{r}
t>0: u=0, \quad \theta=\theta_{T}, \quad C=C_{T} \quad \text { at } y=0 \\
u=0, \quad \theta=0, \quad C=0, \quad \text { as } y=1,
\end{array}
$$

where $\lambda, \gamma, \varepsilon, \delta, \mathrm{Gr}, \mathrm{Gc}, \mathrm{Sr}, \operatorname{Pr}, S, \mathrm{Sc}, \theta_{T}$ and $C_{T}$ are the Frank-Kamenetskii parameter, suction/injection parameter, activation energy parameter, variable thermal conductivity parameter, thermal Grashof number, solutal Grashof number, Soret number, Prandtl number, heat source/sinks parameter, Schmidt number, temperature difference, and concentration difference of the plates, respectively.

\section{Analytical Solutions}

The governing equations (6) presented in the previous section are highly nonlinear and exhibit no analytic solutions. The analytical solutions have played significant role in validating and exploring computer routines of complicated problems. We reduce the governing equations of this problem into a form that can be solved analytically by setting $\partial u / \partial t=0$, $\partial \theta / \partial t=0$ and $\partial C / \partial t=0$ to obtain the steady state version of the problem. Since at steady state no parameter has any significant effect, the steady state solutions of (4) to (6) with the help of (7) and using perturbation method of the form

$$
\begin{gathered}
u=u_{0}+\lambda u_{1}, \\
C=C_{0}+\lambda C_{1}, \\
\theta=\theta_{0}+\lambda \theta_{1}
\end{gathered}
$$

for velocity, concentration, and temperature, respectively, by taking $\theta_{T}=1$ and $C_{T}=1$ can be written as

$$
\begin{aligned}
& u=H_{1}+H_{3} y+H_{2} e^{-\gamma y}+H_{4} e^{h_{1} y}+H_{5} e^{-h_{2} y}+H_{6} e^{-S c \gamma y} \\
& +\lambda\left[H_{7}+H_{9} y+H_{8} e^{-\gamma y}+\left(H_{10}+H_{12}+H_{13} y\right) e^{h_{1} y}\right. \\
& +\left(H_{11}+H_{14}+H_{15} y\right) e^{-h_{2} y}+H_{16} e^{2 h_{1} y} \\
& \left.+H_{17} e^{-2 h_{2} y}+H_{18} e^{\left(h_{1}-h_{2}\right) y}\right] \text {, } \\
& C=E_{1}+E_{2} e^{-S c \gamma y}+E_{3} e^{h_{1} y}+E_{4} e^{-h_{2} y} \\
& +\lambda\left[E_{5}+E_{6} e^{-S c \gamma y}+\left(E_{7}+E_{9}+E_{10} y\right) e^{h_{1} y}\right. \\
& +\left(E_{8}+E_{11}+E_{12} y\right) e^{-h_{2} y}+E_{13} e^{2 h_{1} y} \\
& \left.+E_{14} e^{-2 h_{2} y}+E_{15} e^{\left(h_{1}-h_{2}\right) y}\right] \text {, } \\
& \theta=A e^{h_{1} y}+B e^{-h_{2} y} \\
& +\lambda\left[\left(D_{1}+D_{4} y\right) e^{h_{1} y}+\left(D_{2}+D_{5} y\right) e^{-h_{2} y}+D_{3}\right. \\
& \left.+D_{6} e^{2 h_{1} y}+D_{8} e^{-2 h_{2} y}+D_{7} e^{\left(h_{1}-h_{2}\right) y}\right] \text {. }
\end{aligned}
$$


Using (9), we write the steady state skin friction, Sherwood number, and Nusselt number on the boundaries as

$$
\begin{aligned}
\left.\frac{\partial u}{\partial y}\right|_{y=0}= & -\gamma H_{2}+H_{3}+H_{4} h_{1}-H_{5} h_{2}-H_{6} \mathrm{Sc} \gamma \\
+ & \lambda\left[-\gamma H_{8}+H_{9}+H_{10} h_{1}-H_{11} h_{2}\right. \\
& +H_{12} h_{1}+H_{13}-H_{14} h_{2}+H_{15} \\
& \left.+2 H_{16} h_{1}-2 H_{17} h_{2}+H_{18}\left(h_{1}-h_{2}\right)\right], \\
\left.\frac{\partial u}{\partial y}\right|_{y=1}=H_{3}+ & H_{4} h_{1} e^{h_{1}}-H_{5} h_{2} e^{-h_{2}}-\gamma H_{2} e^{-\gamma}-\mathrm{Sc} \gamma H_{6} e^{-\mathrm{Sc} \gamma} \\
+\lambda[ & H_{9}-\gamma H_{8} e^{-\gamma} \\
& +\left(H_{10} h_{1}+H_{12} h_{1}+H_{13}+H_{13} h_{1}\right) e^{h_{1}} \\
& +\left(H_{15}-H_{15} h_{2}-H_{14} h_{2}+H_{11} h_{2}\right) e^{-h_{2}} \\
& +2 h_{1} H_{16} e^{2 h_{1} y}-2 h_{2} H_{17} e^{-2 h_{2}} \\
& \left.+H_{18}\left(h_{1}-h_{2}\right) e^{\left(h_{1}-h_{2}\right)}\right]
\end{aligned}
$$$$
\left.\frac{\partial C}{\partial y}\right|_{y=0}=-\mathrm{Sc} \gamma E_{2}+E_{3} h_{1}-E_{4} h_{2}
$$$$
+\lambda\left[-\operatorname{Sc} \gamma E_{6}+E_{7} h_{1}-E_{8} h_{2}\right.
$$$$
+E_{9} h_{1}+E_{10}+-E_{11} h_{2}+E_{12}
$$$$
\left.+2 E_{13} h_{1}-2 E_{14} h_{2}+E_{15}\left(h_{1}-h_{2}\right)\right] \text {, }
$$$$
\left.\frac{\partial C}{\partial y}\right|_{y=1}=E_{3} h_{1} e^{h_{1}}-E_{4} h_{2} e^{-h_{2}}-\mathrm{Sc} \gamma E_{2} e^{-\mathrm{Sc} \gamma}
$$$$
+\lambda\left[-\mathrm{Sc} \gamma E_{6} e^{-\mathrm{Sc} \gamma}\right.
$$$$
+\left(E_{7} h_{1}+E_{9} h_{1}+E_{10}+E_{10} h_{1}\right) e^{h_{1}}
$$$$
+\left(E_{12}-E_{12} h_{2}-E_{8} h_{2}-E_{11} h_{2}\right) e^{-h_{2}}
$$$$
+2 h_{1} E_{13} e^{2 h_{1}}+-2 h_{2} E_{14} e^{-2 h_{2}}
$$$$
\left.+E_{15}\left(h_{1}-h_{2}\right) e^{\left(h_{1}-h_{2}\right)}\right] \text {, }
$$$$
\left.\frac{\partial \theta}{\partial y}\right|_{y=0}=A h_{1}-B h_{2}
$$

$$
\begin{gathered}
+\lambda\left[D_{1} h_{1}-D_{2} h_{2}+D_{4}+D_{5}\right. \\
\left.+2 D_{6} h_{1}-2 D_{8} h_{2}+D_{7}\left(h_{1}-h_{2}\right)\right], \\
\left.\frac{\partial \theta}{\partial y}\right|_{y=1}=A h_{1} e^{h_{1}}-B h_{2} e^{-h_{2}} \\
+\lambda\left[\left(D_{1} h_{1}+D_{4}+D_{4} h_{1}\right) e^{h_{1}}\right. \\
+\left(D_{5}-D_{2} h_{2}-D_{5} h_{2}\right) e^{-h_{2}}+2 h_{1} D_{6} e^{2 h_{1}}
\end{gathered}
$$

$$
\left.-2 D_{8} h_{2} e^{-2 h_{2}}+D_{7}\left(h_{1}-h_{2}\right) e^{\left(h_{1}-h_{2}\right)}\right]
$$

The constants $h_{1}, h_{2}, A, B, H_{1}, H_{2}, H_{3}, H_{4}, H_{5}, H_{6}, H_{7}, H_{8}$, $H_{9}, H_{10}, H_{11}, H_{12}, H_{13}, H_{14}, H_{15}, H_{16}, H_{17}, H_{18}, E_{1}, E_{2}, E_{3}$, $E_{4}, E_{5}, E_{6}, E_{7}, E_{8}, E_{9}, E_{10}, E_{11}, E_{12}, E_{13}, E_{14}, E_{15}$, and $D_{1}, D_{2}$, $D_{3}, D_{4}, D_{5}, D_{6}, D_{7}$ are defined in the appendix section.

\section{Numerical Solutions}

The set of partial differential equations (4) to (6) with the boundary conditions (7) are solved numerically using semiimplicit finite difference scheme given in [27]. We used forward difference formulas for all time derivatives and approximated both the second and first derivatives with second order central differences. The semi-implicit finite difference equation corresponding to (4) to (6) is as follows:

$$
\begin{aligned}
- & r_{1} u_{j-1}^{(N+1)}+\left(1+2 r_{1}\right) u_{j}^{(N+1)}-r_{1} u_{j+1}^{(N+1)} \\
= & \left(r_{2}-r_{3}\right) u_{j-1}^{(N)}+\left(1-2 r_{2}\right) u_{j}^{(N)} \\
& +\left(r_{2}+r_{3}\right) u_{j+1}^{(N)}+\Delta t \mathrm{Gr} \theta_{j}^{N}+\Delta t \mathrm{Gc} C_{j}^{N}, \\
-r_{1} C_{j-1}^{(N+1)}+\left(\mathrm{Sc}+2 r_{1}\right) C_{j}^{(N+1)}-r_{1} C_{j+1}^{(N+1)} & \left(r_{2}-\mathrm{Sc}_{3}\right) C_{j-1}^{(N)}+\left(\mathrm{Sc}-2 r_{2}\right) C_{j}^{(N)} \\
& +\left(r_{2}+\operatorname{Sc} r_{3}\right) C_{j+1}^{(N)}+r_{4}\left(\theta_{j-1}^{N}-2 \theta_{j}^{N}+\theta_{j+1}^{N}\right), \\
-s_{1} \theta_{j-1}^{(N+1)}+\left(\operatorname{Pr}+2 s_{1}\right) \theta_{j}^{(N+1)}-s_{1} \theta_{j+1}^{(N+1)} & \left(s_{2}-\operatorname{Pr} r_{3}\right) \theta_{j-1}^{(N)}+\left(\operatorname{Pr}-2 s_{2}+S \Delta t\right) \theta_{j}^{(N)} \\
& +\left(s_{2}+\operatorname{Pr} r_{3}\right) \theta_{j+1}^{(N)}+s_{3}\left(\theta_{j+1}^{(N)}-\theta_{j-1}^{(N)}\right)^{2} \\
& +\lambda \Delta t \exp \left(\frac{\theta_{j}^{(N)}}{1+\varepsilon \theta_{j}^{(N)}}\right),
\end{aligned}
$$

where $r_{1}=\xi \Delta t / \Delta y^{2}, r_{2}=(1-\xi) \Delta t / \Delta y^{2}, r_{3}=\gamma \Delta t / 2 \Delta y$, $r_{4}=\operatorname{Sr} \Delta t / \Delta y^{2}, s_{1}=\xi \Delta t q / \Delta y^{2}, s_{2}=(1-\xi) \Delta t q / \Delta y^{2}$, $s_{3}=\delta \Delta t / 4 \Delta y^{2}, q=1+\delta \theta_{j}^{N}$, and $0 \leq \xi \leq 1$. We chose $\xi=1$; the detailed reasons to this particular selection are documented in [27]. Also the analytical solutions displayed in the previous section are used as a check on the accuracy and effectiveness of the numerical scheme. Again, in order to reconfirm the accuracy of the scheme, the numerical results for velocity, concentration, and temperature are compared with the analytical solutions. At larger time a steady state condition is reached; as can be seen in Figure 2, an excellent agreement is reached between these results.

\section{Results and Discussion}

The numerical results are obtained by solving (4) to (6) using the method described in the previous section for various values of physical parameters to describe the physics of the 


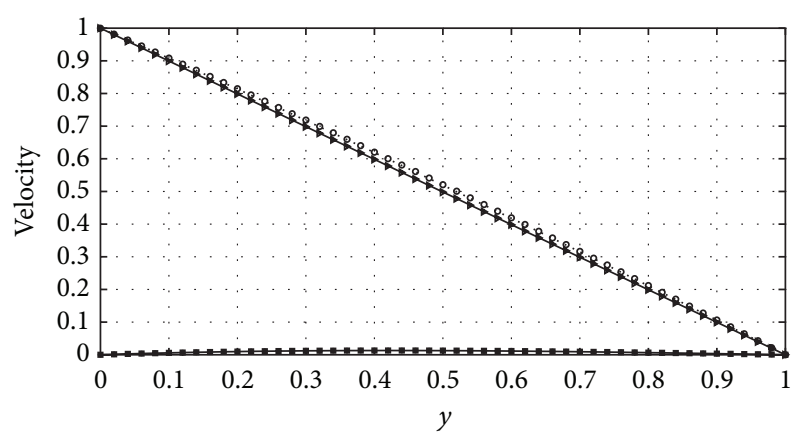

—- Num. soln. for velocity at steady state

- Steady state anal. soln. for velocity

.... Num. soln. for temp. at steady state

- Steady state anal. for temp.

- Num. soln. for conc. at steady state

- Steady state anal. for conc.

FIgURE 2: Unsteady and steady state solutions for velocity, temperature, and concentration profiles.

problem. Unless otherwise stated, the values $\lambda=0.1, \mathrm{Gr}=1$, $\mathrm{Gc}=1, \mathrm{Sr}=0.1, \theta_{T}=1, C_{T}=1, \operatorname{Pr}=0.71, \delta=0.1, S$ $=0.1, t=0.1,(\gamma=5$ suction and $\gamma=-5$ injection $), \mathrm{Sc}$ $=0.62$, and $\varepsilon=0.01$ are used for the investigation. Results obtained are displayed graphically for velocity, temperature, concentration, skin friction, Nusselt number, and Sherwood number for various flow parameters.

Figures 3(a) and 3(b) show the effects of the FrankKamenetskii parameter $(\lambda)$ and suction/injection parameter $(\gamma)$ on the temperature distribution, respectively. From Figure 3(a) it is observed that temperature of the fluid increases with increasing values of $\lambda$ in case of suction and injection. This is true since an increase in $\lambda$ leads to significant increases in the reaction and viscous source terms and hence considerably increases the fluid temperature. It is evident from Figure 3(a) that temperature of the fluid is greater in case of injection than suction. From Figure 3(b) it is seen that temperature decreases due to suction but increases due to injection. In case of suction the fluid at ambient conditions is brought closer to the surface and reduces the thermal boundary layer thickness. The same principle operates but in reverse direction in case of injection. Figures 4(a) and 4(b) illustrated the effects of the Frank-Kamenetskii parameter $(\lambda)$ and suction/injection parameter $(\gamma)$ on velocity profiles, respectively. Figure 4 (a) revealed that increasing $\lambda$ accelerates the fluid velocity in case of suction and injection. Further, it can be seen that velocity is high in case of injection than suction. From Figure 4(b) it is seen that velocity of the fluid decelerates due to suction while accelerates due to blowing. The physical explanation for such a behavior is that while stronger blowing is provided, the heated fluid is pushed farther from the wall where the buoyancy forces can act to accelerate the flow with less influence of the viscosity. The same principle operates but in opposite direction in case of suction.

Figures 5(a) and 5(b) represent the velocity distribution of fluid for various values of Soret number (Sr) and heat generation/absorption parameter $(S)$, respectively. It can be noticed that values of $\mathrm{Sr}$ accelerate the fluid velocity in the presence of suction and injection. In Figure 5(a) it is observed that velocity of the fluid moves toward the left porous plate in case of suction, while in case of injection the maximum velocities move towards the right porous plate. From Figure 5(b) it is noted that positive values of $S$, that is, $(S>0)$, result in the heating of the fluid which leads to the increase in the fluid velocity while negative values of $S$, that is, $(S<0)$, result in the cooling of the fluid which leads to the decrease in the fluid velocity. Figures 6(a) and 6(b) illustrated the influence of $\mathrm{Sr}$ and $\gamma$ on concentration distribution, respectively. In Figure 6(a) it is observed that concentration of the fluid increases with increasing values of $\mathrm{Sr}$ in case of suction and injection. Figure 6(a) revealed that concentration of the fluid is higher in the vicinity of the wall $y=0$, where suction takes place, than at the wall $y=1$ where injection takes place. From Figure 6(b), the concentration of the fluid decreases due to suction but increases due to injection.

Figures 7(a) and 7(b) displayed the influence of heat generation/absorption $(S)$ and variable thermal conductivity parameter $(\delta)$ on temperature field, respectively. From Figure 7 (a) it is noted that temperature of the fluid increases when $S>0$ and decreases when $S<0$ in case of suction and injection. This is physically true since $S>0$ correspond to the cooling of the fluid while $S<0$ correspond to the heating of the fluid. Growing values of $\delta$ increase temperature of the fluid in case of suction and injection; see Figure 7(b). The influence of the thermal Grashof number (Gr) and mass Grashof number (Gc) is illustrated in Figures 8(a) and 8(b), respectively. These plots (Figures $8(\mathrm{a})$ and $8(\mathrm{~b})$ ) indicate that the momentum boundary layer thickness increases with increasing Gr and Gc. It is further noticed from the figures that velocity of the fluid is greater in case of injection than suction. Figure 9 is plotted to see the effects of $\delta$ on velocity field. Velocity of the fluid increases with increasing $\delta$ in case of suction and injection. An insignificant effect is observed in case of injection.

The wall shear stress and wall heat transfer rate dependence on Frank-Kamenetskii parameter, $\lambda$, for varying values of nondimensional time are illustrated in Figures 10(a) and 10(b), respectively. From Figure 10(a), it is noted that as time increases, the frictional force due to the motion of the fluid also increases until a steady state is attained. Higher values of $\lambda$ increase the skin friction. A similar trend is observed in the Nusselt number; see Figure 10(b). Figures 11(a) and 11(b) illustrated the wall shear stress and Nusselt number dependence on heat source/sinks parameter, $S$, for varying values of nondimensional time. From these figures it is seen that as time increases, the skin friction and Nusselt number increase until a steady state condition is reached. Also, it is observed that both skin friction and Nusselt number increase with increasing values of the heat source/sinks parameter $S$. Figures 12(a) and 12(b) represent the skin friction and Nusselt number dependence on variable thermal conductivity, $\delta$, for varying values of dimensionless time, respectively. From these plots it is noted that both skin friction and wall heat transfer rate increase by increasing nondimensional time 

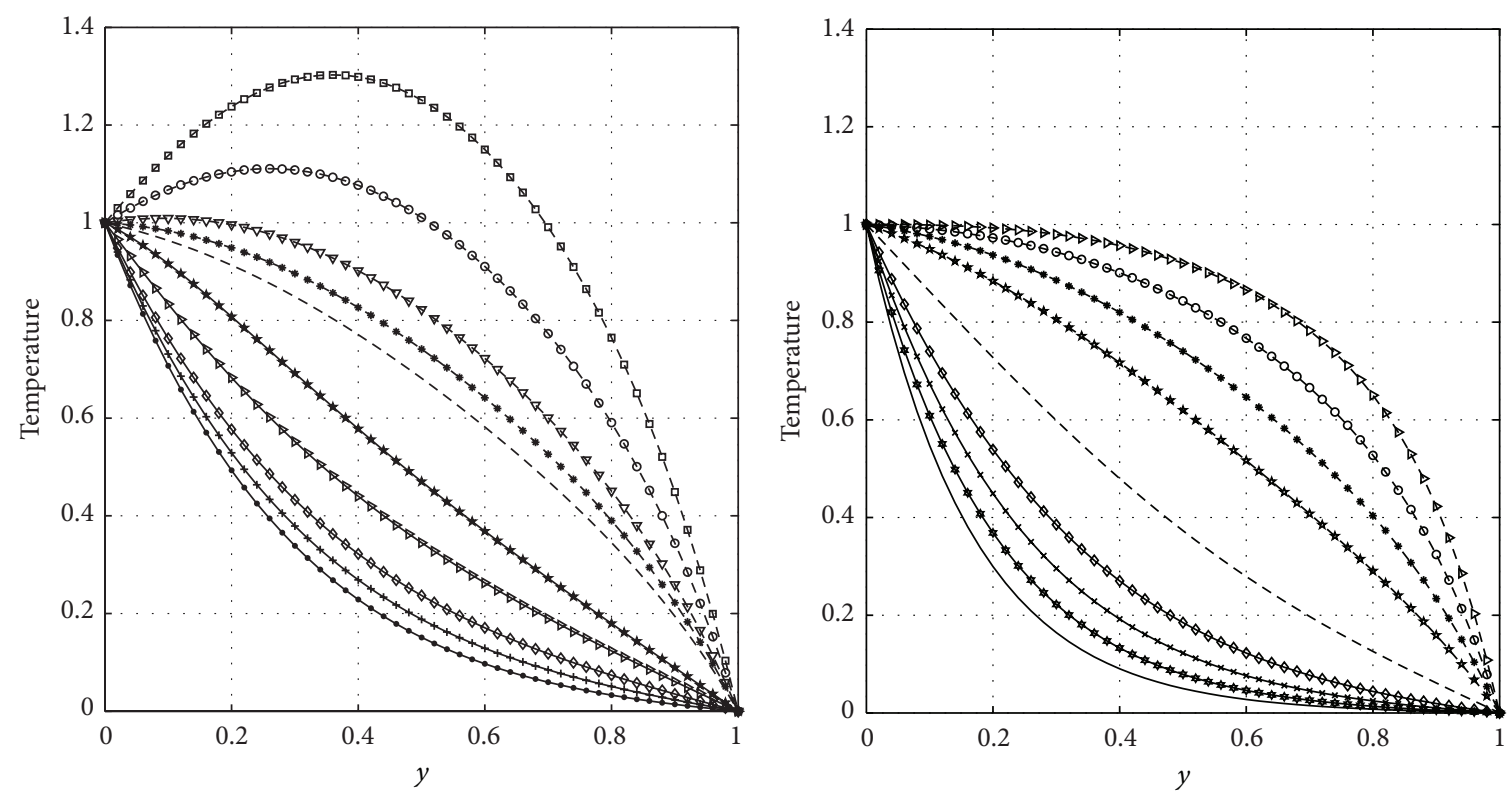

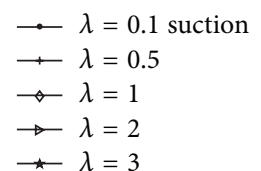

(a)

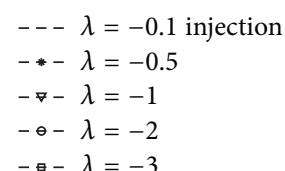

$-\approx-\lambda=-3$

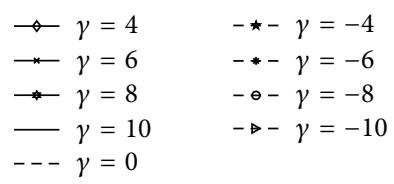

(b)

FIGURE 3: Effects of Frank-Kamenetskii parameter $(\lambda)$ and suction/injection $(\gamma)$ on temperature.

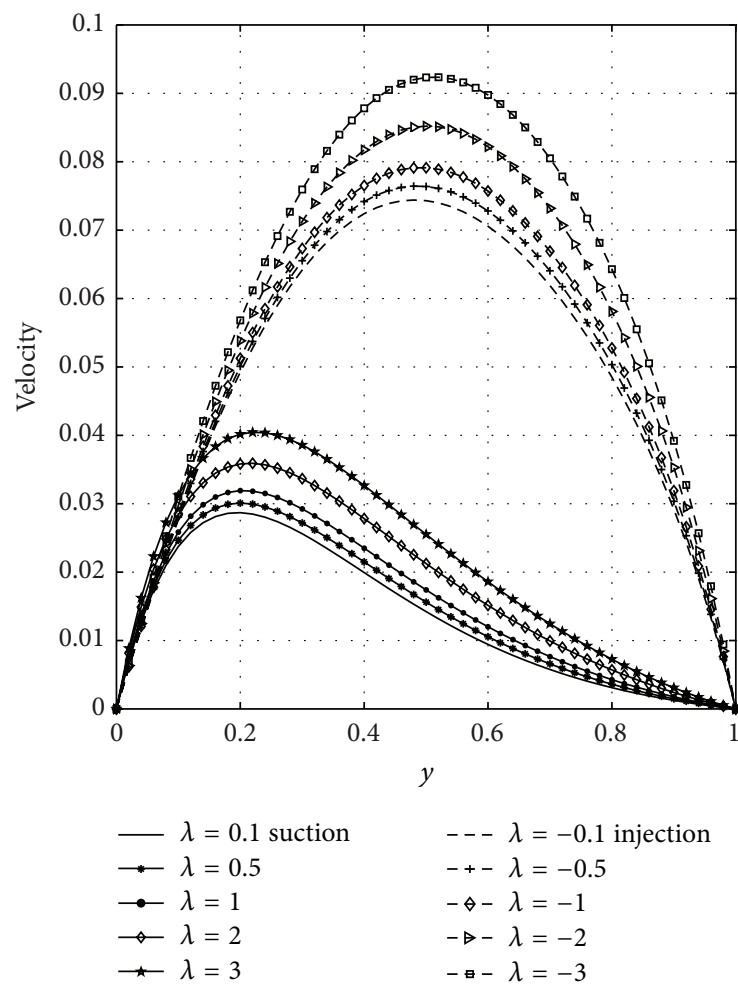

(a)
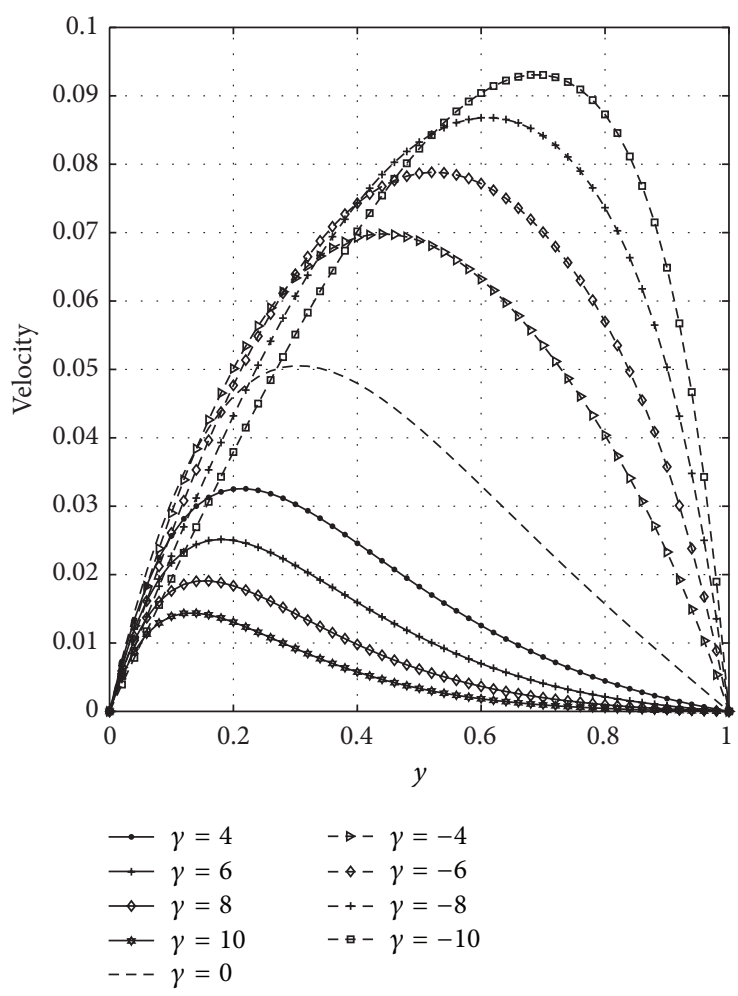

(b)

FIGURE 4: Effects of Frank-Kamenetskii parameter $(\lambda)$ and suction/injection $(\gamma)$ on velocity. 


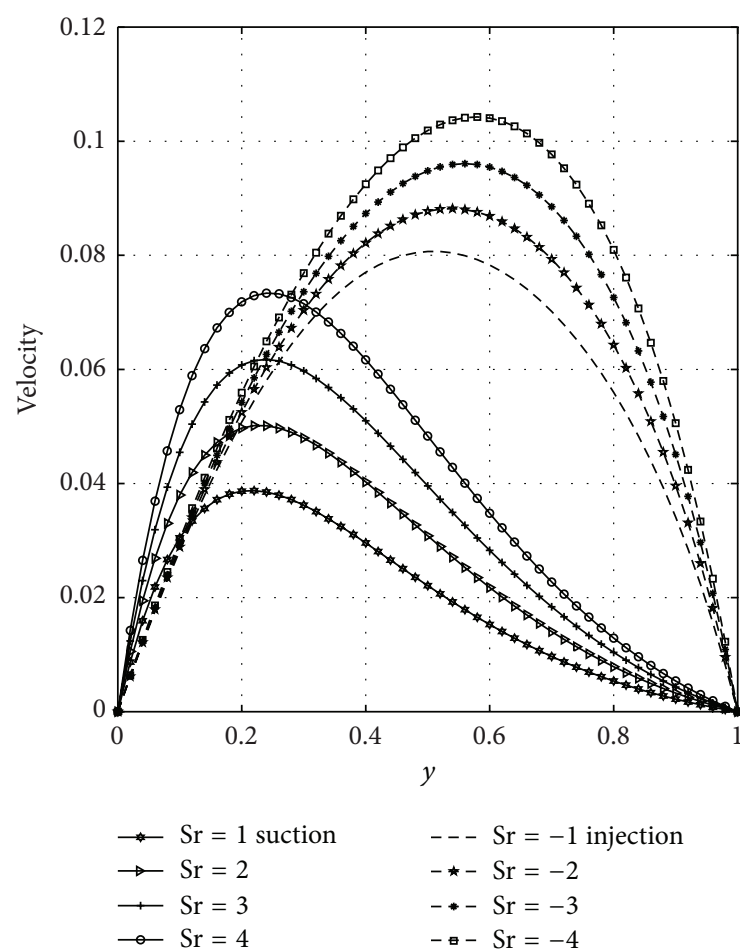

(a)

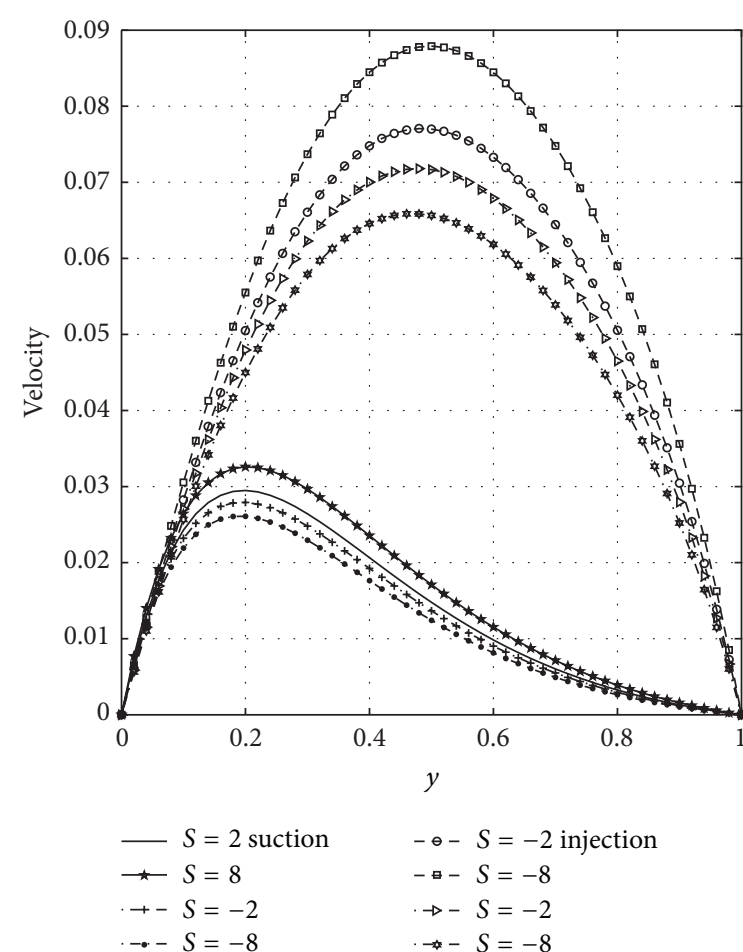

(b)

FIGURE 5: Effects of Soret number ( $\mathrm{Sr}$ ) and heat source/sinks $(S)$ on velocity.

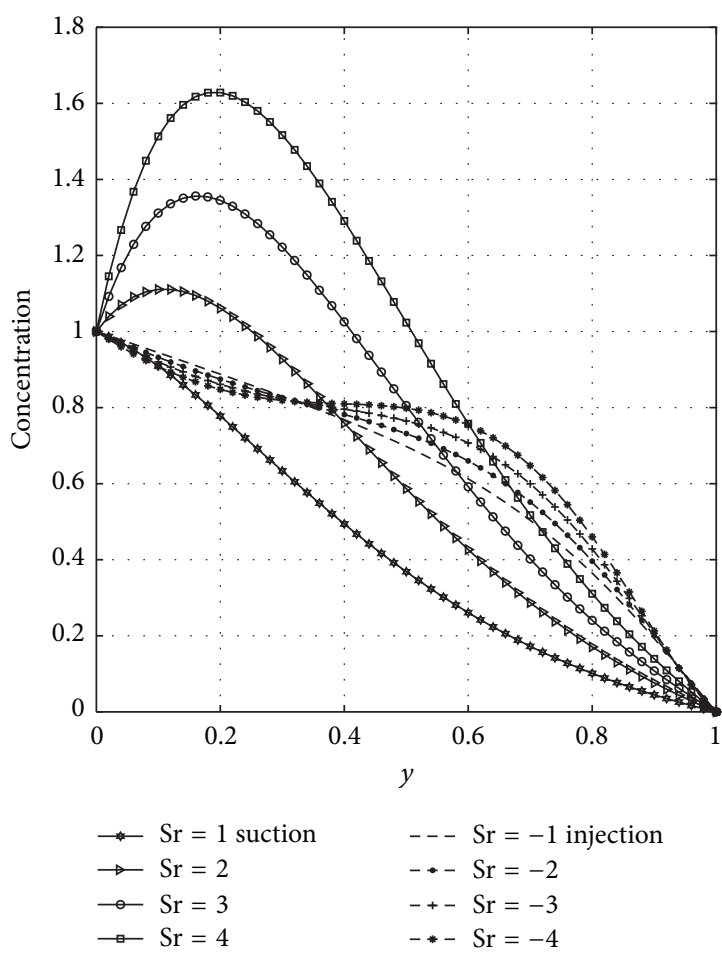

(a)

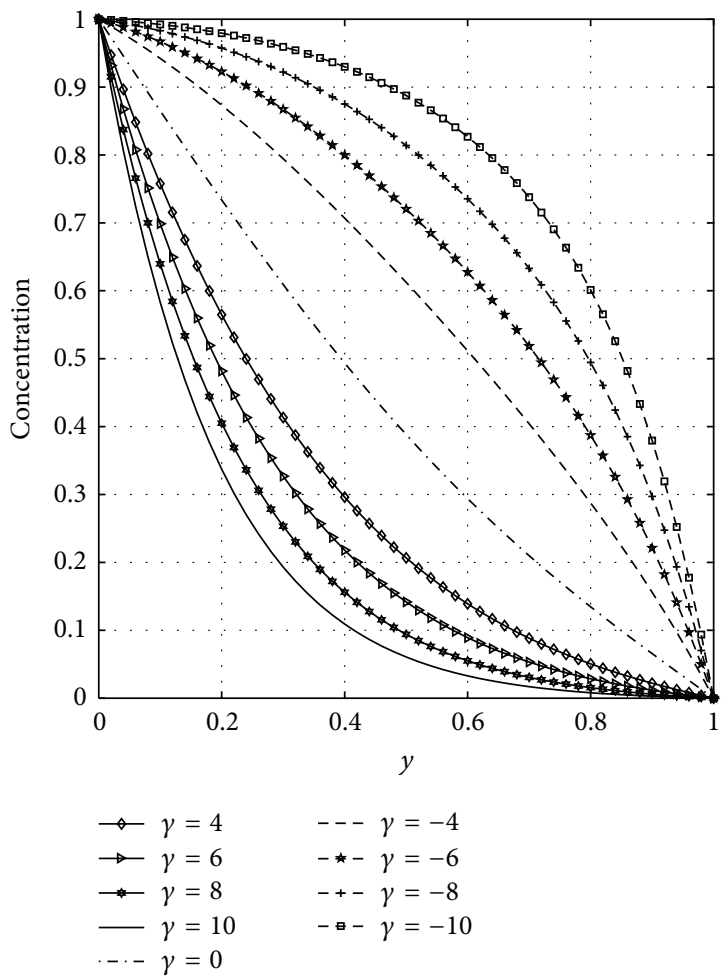

(b)

FIGURE 6: Effects of Soret number ( $\mathrm{Sr})$ and suction/injection $(\gamma)$ on concentration. 


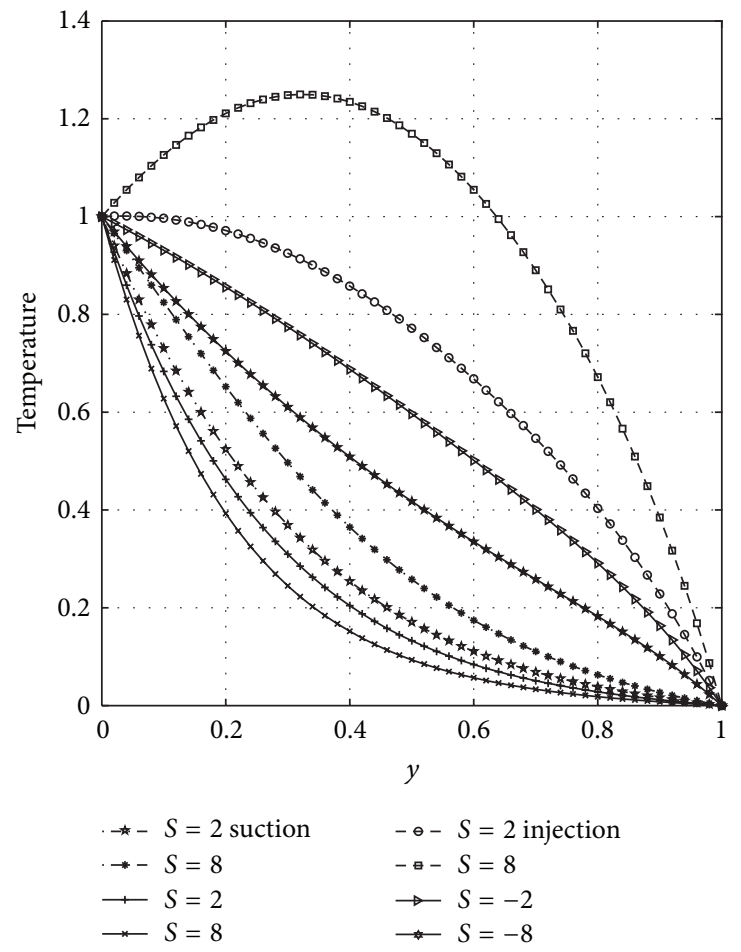

(a)
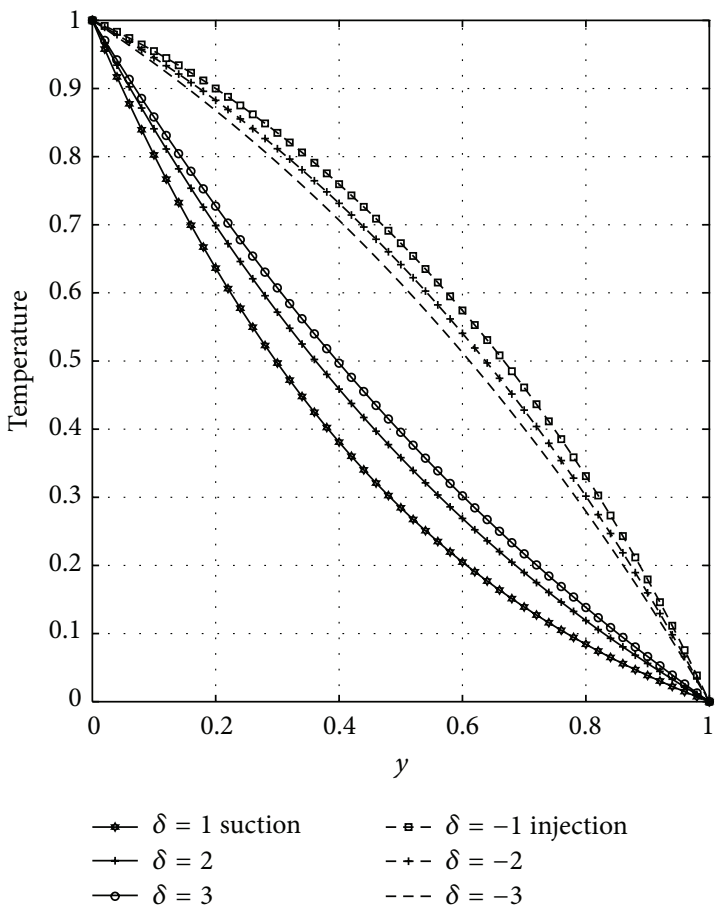

(b)

FIGURE 7: Effects of heat source/sinks $(S)$ and variable thermal conductivity $(\delta)$ on temperature.

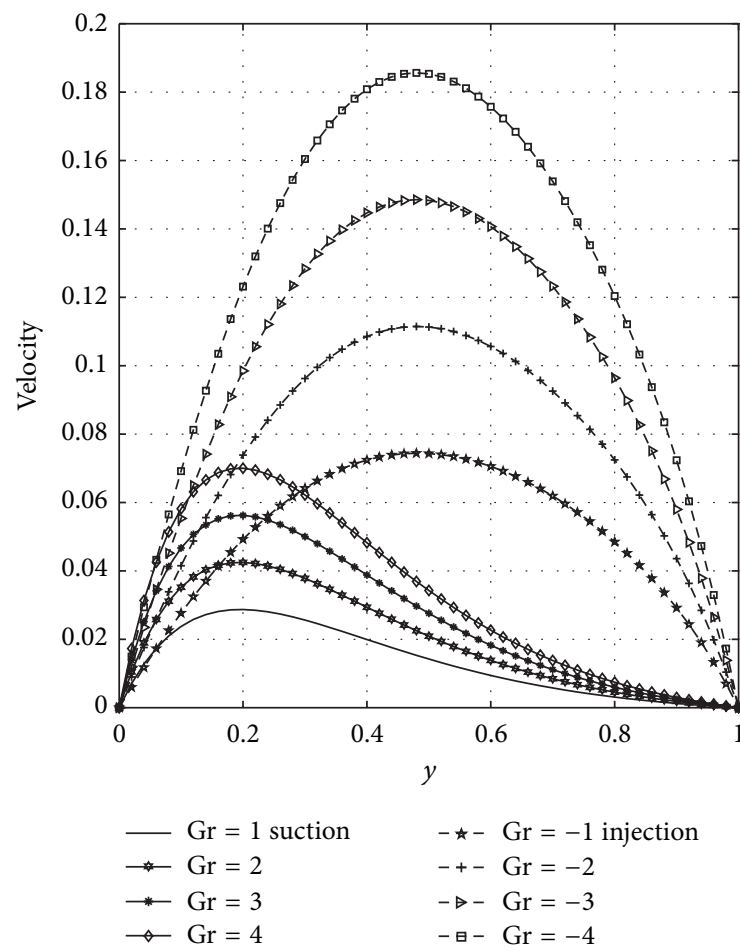

(a)

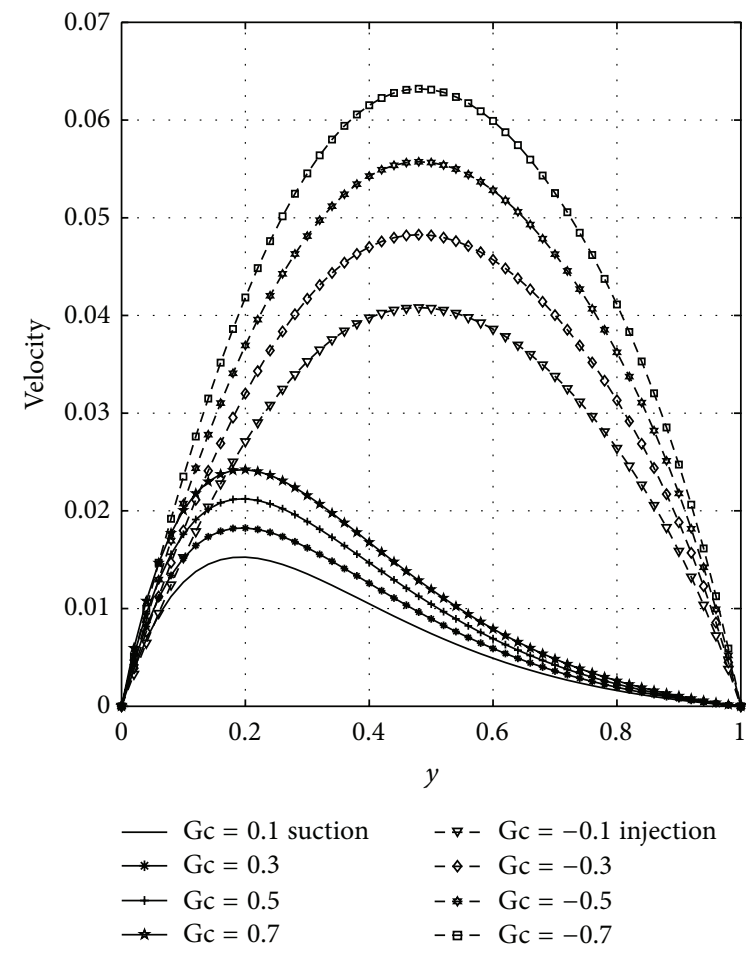

(b)

FIGURE 8: Effects of thermal Grashof number (Gr) and mass Grashof number (Gc) on velocity. 


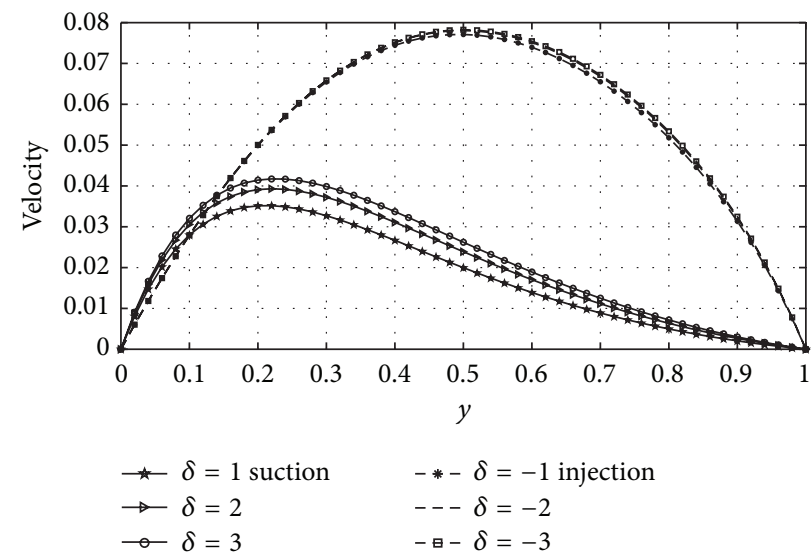

FIGURE 9: Effects of variable thermal conductivity $(\delta)$ on velocity.

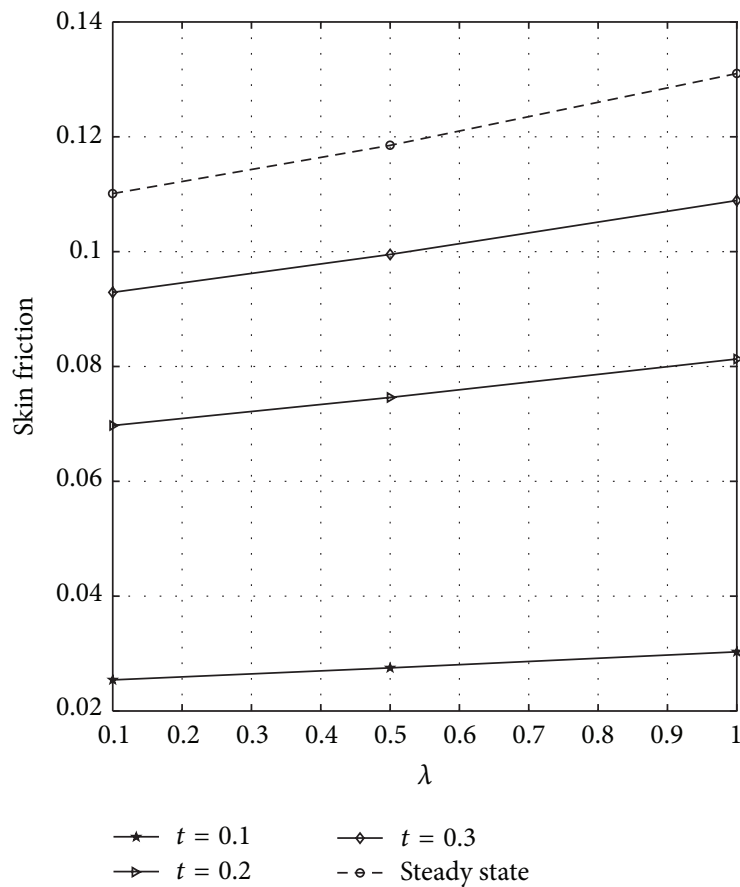

(a)

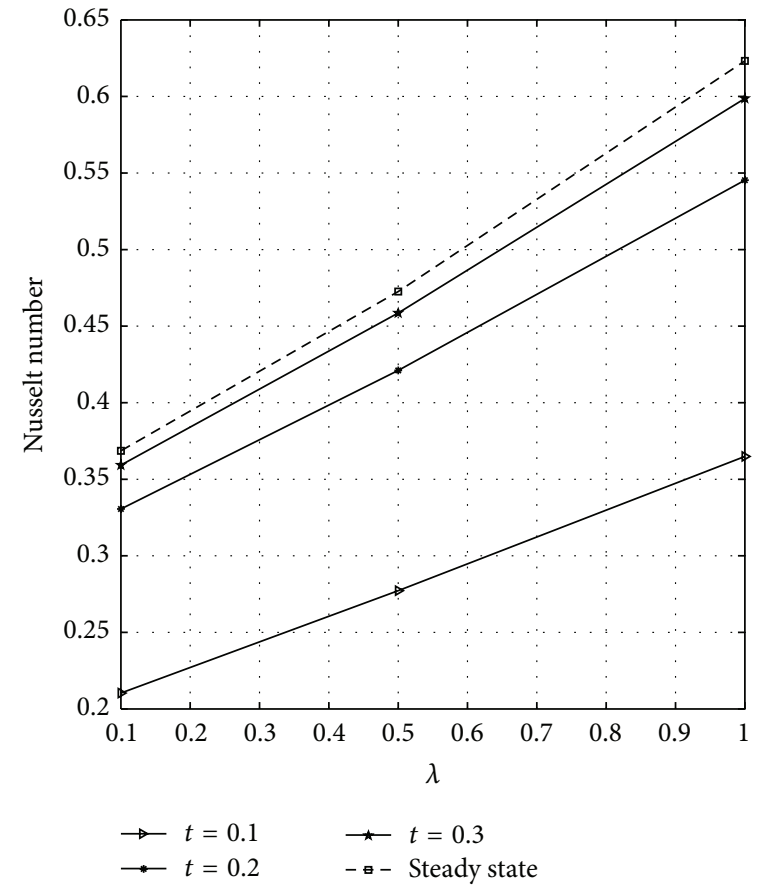

(b)

Figure 10: Variation of skin friction and Nusselt number with $\lambda$ and time $(t)$ at $y=1$.

until a steady state is attained. Figure 12(a) revealed that variable thermal conductivity has no significant effect on the skin friction. In Figure 12(b) it is observed that increasing variable thermal conductivity leads to the increase in the wall heat transfer rate.

Figures 13(a) and 13(b) show the influence of Soret number, Sr, on the skin friction and Sherwood number, respectively. Figure 13(a) reveals that the skin friction increases with increasing $\mathrm{Sr}$ and nondimensional time. The rate of mass transfer decreases with increasing $\mathrm{Sr}$ and time; see Figure 13(b). The wall shear stress dependence on Gr and Gc is illustrated in Figures 14(a) and 14(b) for varying values of dimensionless time. From the two figures it is clear that the skin friction increases as time, Gr, and Gc increase until a steady state value is achieved. The wall shear stress dependence on suction/injection parameter, $\gamma$, is illustrated in Figure 15(a) for varying values of time. It is seen from the figure that skin friction increases as time increases until a steady state is reached. It is also evident that larger values of suction/injection parameter lead to the reduction of the skin friction. The wall heat transfer rate dependence on $\gamma$ is displayed in Figure 15(b) for varying values of time. It is clear from the figure that rate of heat transfer increases as time increases until a steady state value is achieved. It is also observed that higher values of $\gamma$ decrease the rates of heat transfer. Figure 15(c) shows the influence of $\gamma$ and time on 


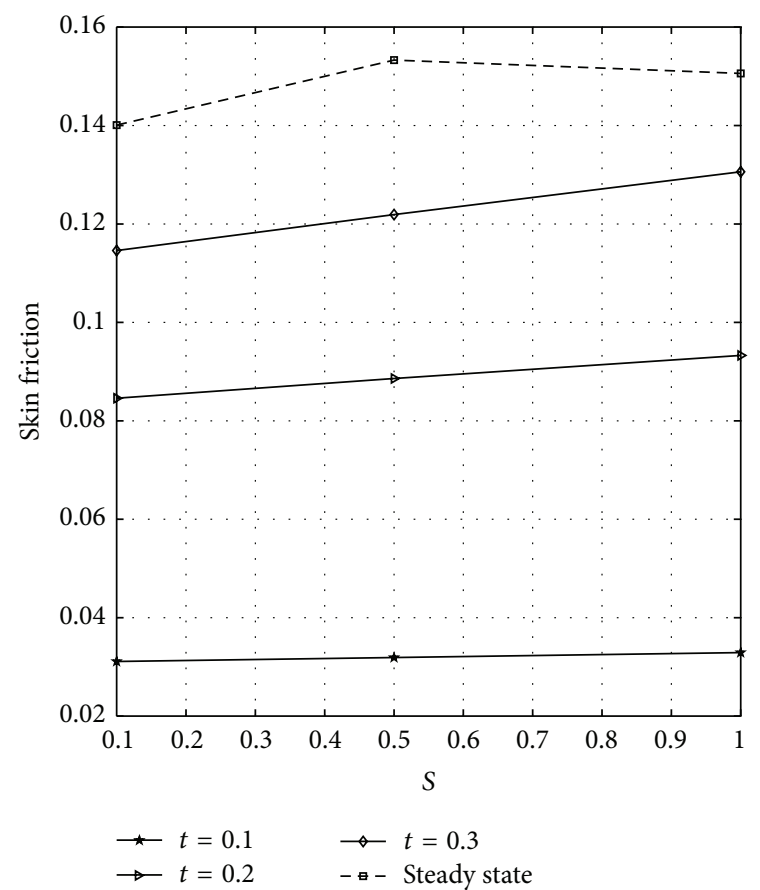

(a)

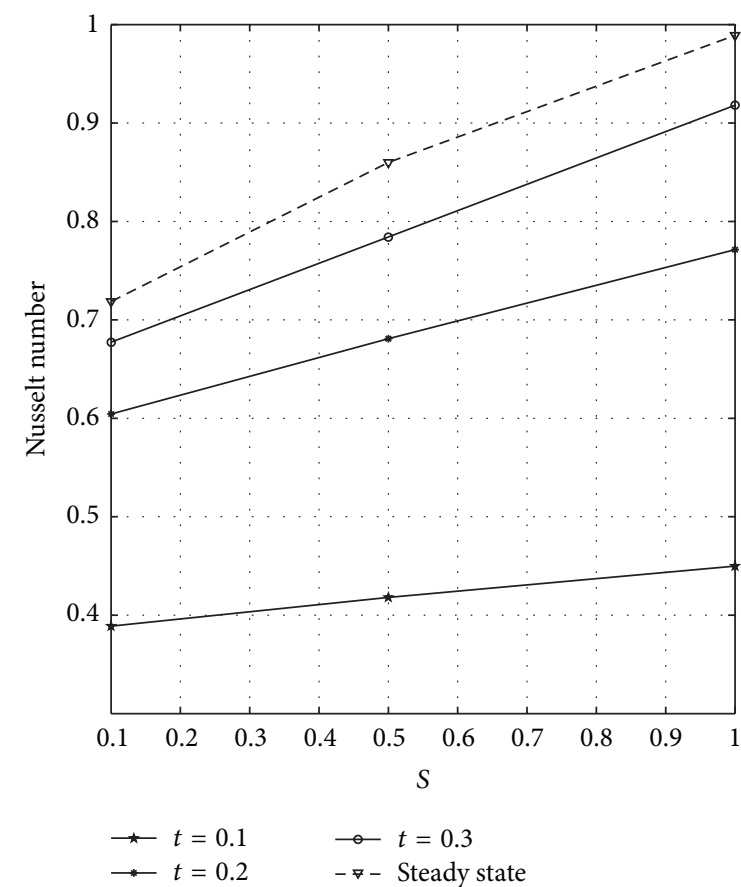

(b)

FIgURE 11: Variation of skin friction and Nusselt number with $\mathrm{S}$ and time $(t)$ at $y=1$.

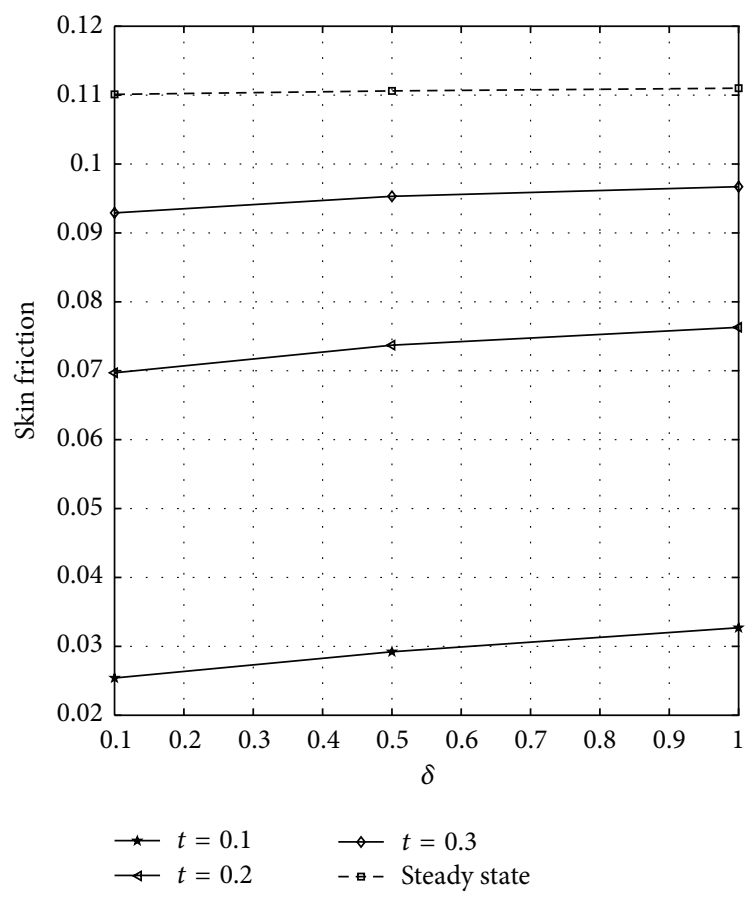

(a)

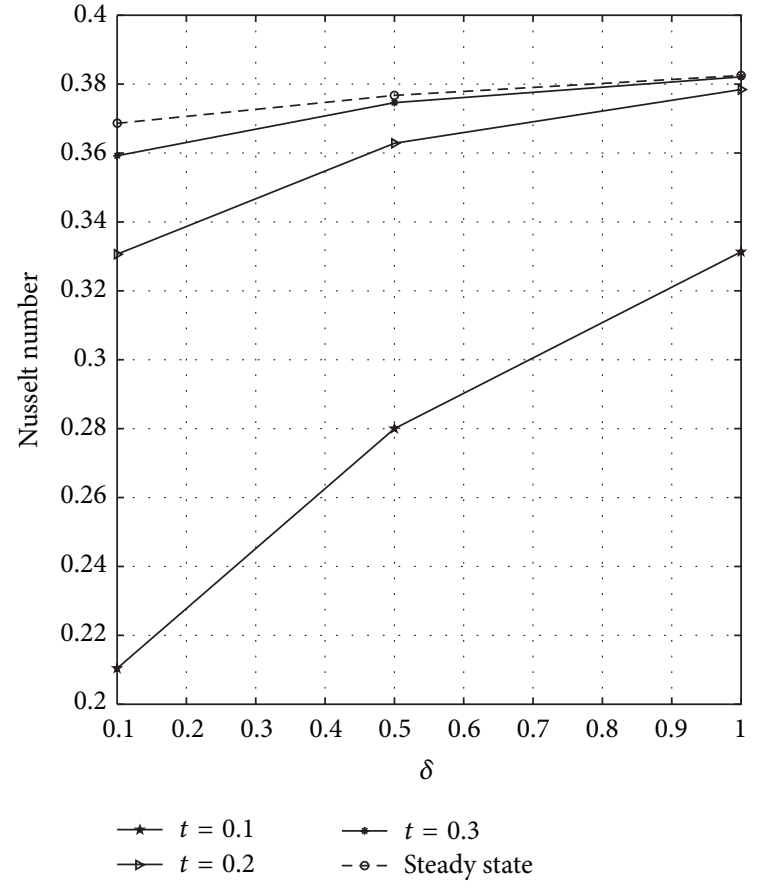

(b)

Figure 12: Variation of skin friction and Nusselt number with $\delta$ and time $(t)$ at $y=1$. 


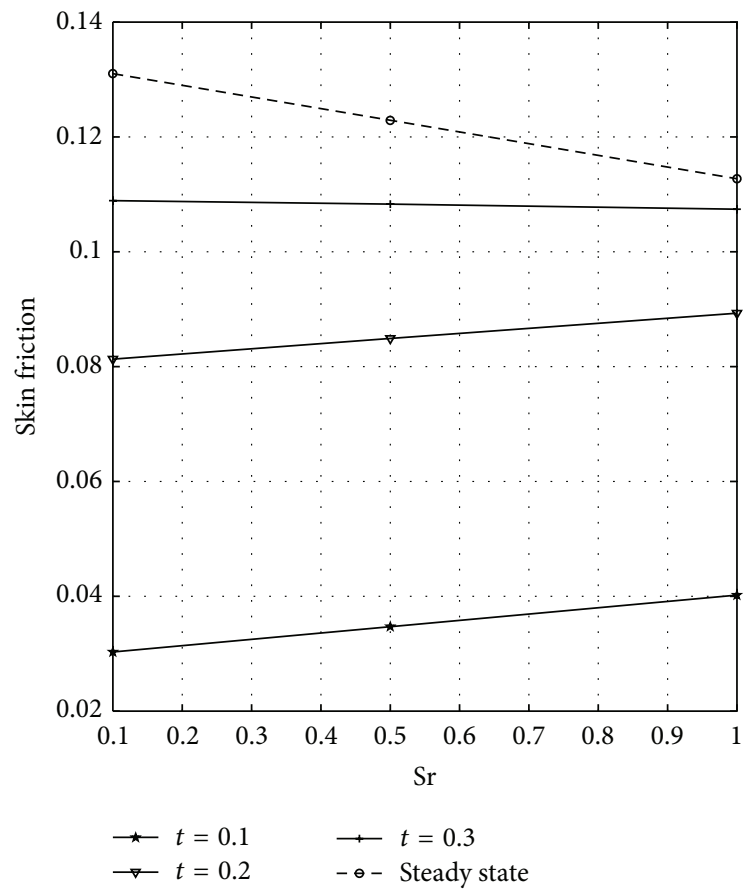

(a)

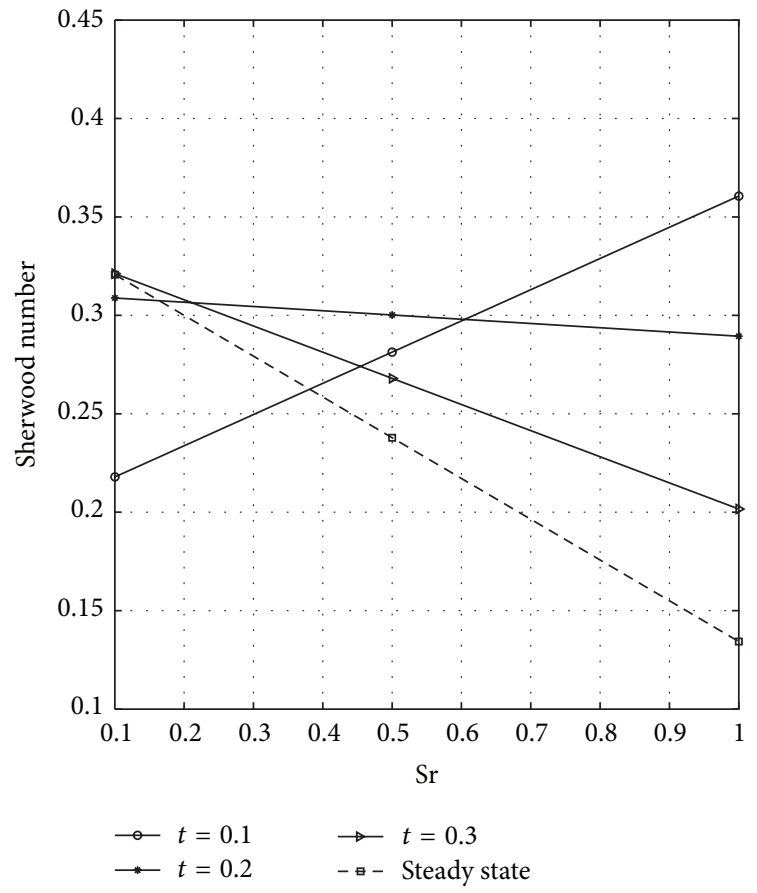

(b)

FIGURE 13: Variation of skin friction and Sherwood number with $\mathrm{Sr}$ and time $(t)$ at $y=1$.

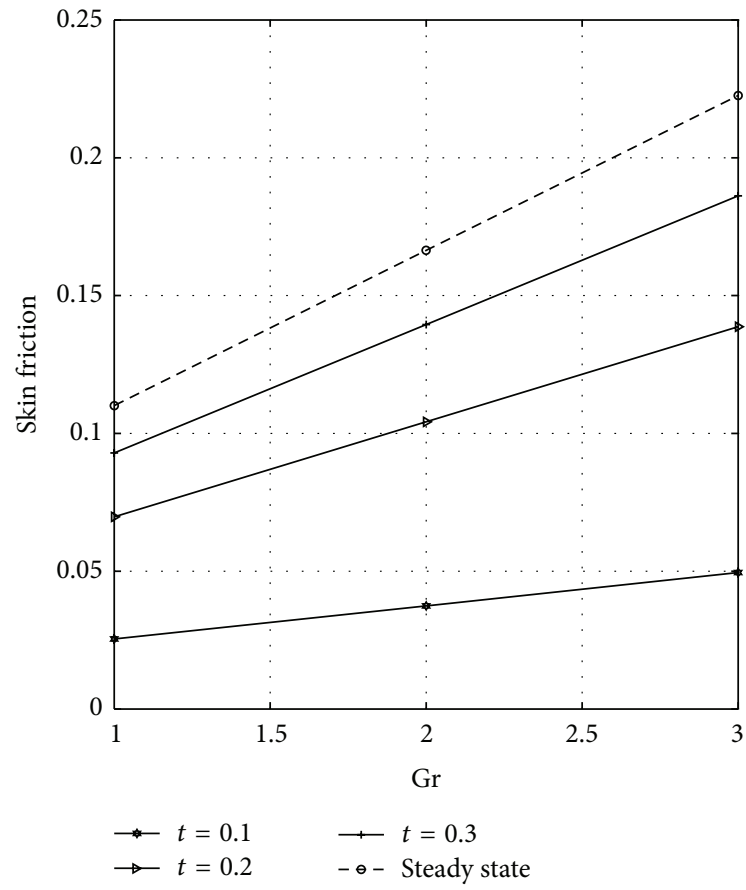

(a)

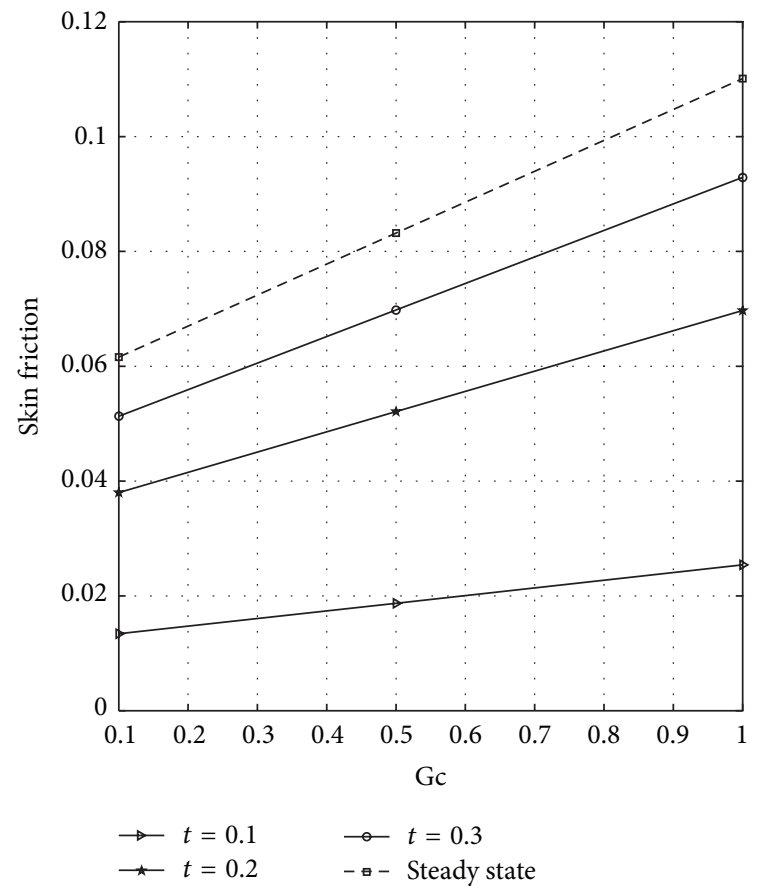

(b)

FIgURE 14: Variation of skin friction with Gr and Gc with time $(t)$ at $y=1$. 


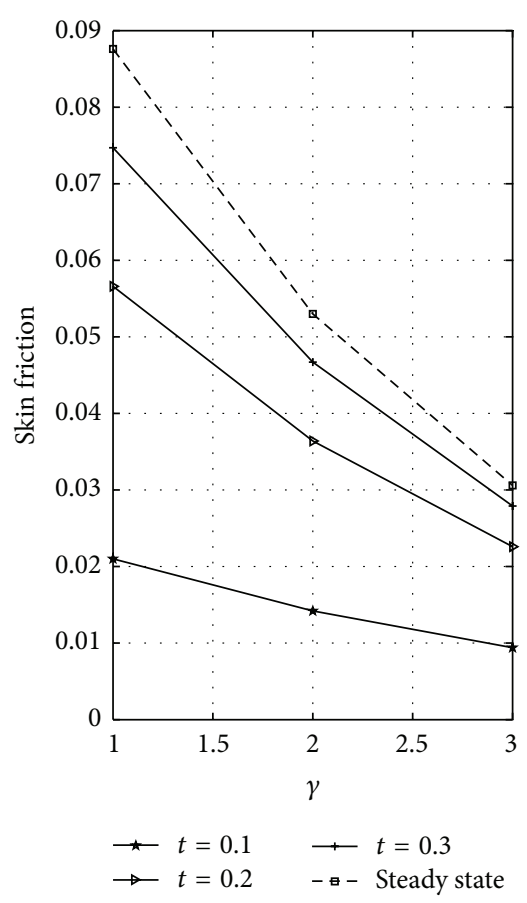

(a)

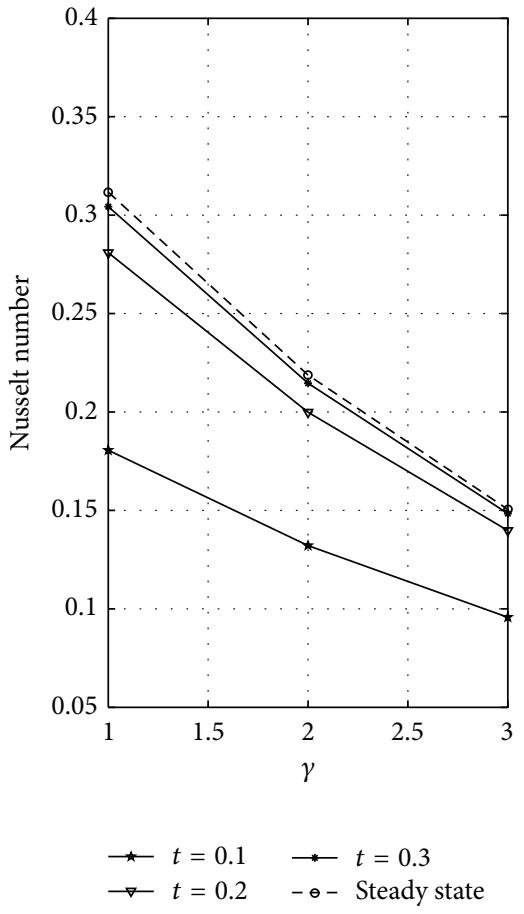

(b)

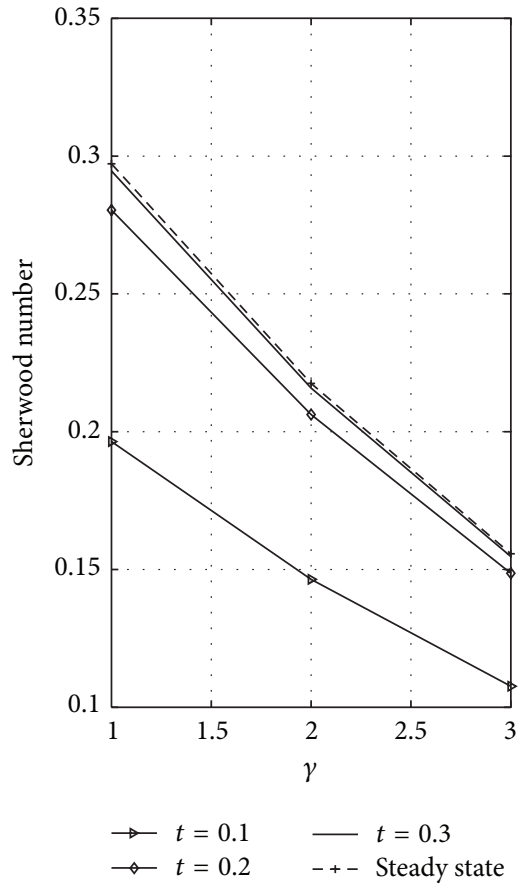

(c)

Figure 15: Variation of skin friction, Nusselt number, and Sherwood number with $\gamma$ and time $(t)$ at $y=1$.

the Sherwood number. It is noted that as time increases, the Sherwood number also increases until a steady state is attained. It is also evident from this figure that higher values of $\gamma$ reduce the Sherwood number.

\section{Conclusion}

In the present study, the effects of suction/injection, heat source/sinks, Soret number, Frank-Kamenetskii parameter, Prandtl number, variable thermal conductivity, and buoyancy parameters on unsteady natural convection and mass transfer flow of viscous reactive, heat generating/absorbing fluid in a vertical channel formed by two infinite vertical porous plates have been investigated. The main findings are as follows.

(i) The numerical simulations show that increasing heat sink parameter decreases the fluid temperature and velocity while increasing heat source parameter increases both the fluid temperature and velocity.

(ii) Suction/injection has distorted the symmetric nature of the flow, as the thermal boundary layer is increasing towards the wall with injection and reducing towards the wall with suction.

(iii) There is an increase in both fluid temperature and velocity with an increase in the reaction strength and variable thermal conductivity while higher values of Prandtl number reduce both temperature and velocity of the fluid.

(iv) An increase in the Soret number increases the velocity and concentration of the channel.

\section{Appendix}

$$
\begin{aligned}
& h_{1}=\frac{-\gamma \operatorname{Pr}+\sqrt{\operatorname{Pr}^{2} \gamma^{2}-4 S}}{2}, \\
& h_{2}=\frac{\gamma \operatorname{Pr}+\sqrt{\operatorname{Pr}^{2} \gamma^{2}-4 S}}{2}, \\
& B=\frac{-e^{h_{1}}}{e^{-h_{2}}-e^{h_{1}}}, \quad D_{6}=-\frac{A^{2} a}{4 h_{1}^{2}+\gamma \operatorname{Pr} h_{1}+S}, \\
& D_{7}=\frac{2 A B a}{\left(h_{1}-h_{2}\right)^{2}+\gamma \operatorname{Pr}\left(h_{1}-h_{2}\right)+S} A=1-B \quad a=\varepsilon-\frac{1}{2} \text {, } \\
& D_{5}=-\frac{B}{\gamma \operatorname{Pr}-2 h_{2}}, \quad D_{4}=-\frac{A}{2 h_{1}+\gamma \operatorname{Pr}}, \\
& D_{8}=-\frac{B a}{4 h_{2}^{2}-2 \gamma \operatorname{Pr} h_{2}+S}, \\
& D_{1}=-D_{2}-D_{3}-D_{6}-D_{7}-D_{8} \text {, } \\
& E_{1}=1-E_{2}-E_{3}-E_{4}, \quad D_{3}=-\frac{1}{S} \\
& D_{2}=\frac{-D_{3}\left(1-e^{h_{1}}\right)}{\left(e^{-h_{2}}-e^{h_{1}}\right)}-\frac{D_{4} e^{h_{1}}}{\left(e^{-h_{2}}-e^{h_{1}}\right)}
\end{aligned}
$$




$$
\begin{aligned}
& -\frac{D_{5} e^{-h_{2}}}{\left(e^{-h_{2}}-e^{h_{1}}\right)}-\frac{D_{6}\left(e^{2 h_{1}}-e^{h_{1}}\right)}{\left(e^{-h_{2}}-e^{h_{1}}\right)} \\
& -\frac{D_{7}\left(e^{h_{1}-h_{2}}-e^{h_{1}}\right)}{\left(e^{-h_{2}}-e^{h_{1}}\right)}-\frac{D_{8}\left(e^{-2 h_{2}}-e^{h_{2}}\right)}{\left(e^{-h_{2}}-e^{h_{1}}\right)} \\
& g_{1}=D_{1} h_{1}^{2}+2 D_{4} h_{1}, \quad g_{2}=D_{2} h_{2}^{2}-2 D_{5} h_{2}, \\
& g_{3}=D_{4} h_{1}^{2}, \quad g_{4}=D_{5} h_{2}^{2}, \quad g_{5}=4 D_{6} h_{1}^{2} \text {, } \\
& g_{6}=8 D_{8} h_{2}^{2}, \quad g_{7}=D_{7}\left(h_{1}-h_{2}\right)^{2}, \\
& E_{3}=-\frac{\mathrm{Sr} A h_{1}^{2}}{h_{1}^{2}+\mathrm{Sc} \gamma h_{1}}, \quad E_{4}=-\frac{\mathrm{Sr} B h_{2}^{2}}{h_{2}^{2}-\mathrm{Sc} \gamma h_{2}}, \\
& E_{8}=-\frac{\mathrm{Sr} g_{2}}{h_{2}^{2}-\mathrm{Sc} \gamma h_{2}}, \quad E_{11}=-\frac{E_{12}\left(\mathrm{Sc} \gamma-2 h_{2}\right)}{h_{2}^{2}-\mathrm{Sc} \gamma h_{2}} \text {, } \\
& E_{2}=\frac{-1}{\left(e^{-S c \gamma}-1\right)}-\frac{E_{3}\left(e^{h_{1}}-1\right)}{\left(e^{-S c \gamma}-1\right)}-\frac{E_{4}\left(e^{-h_{2}}-1\right)}{\left(e^{-S c \gamma}-1\right)}, \\
& E_{7}=-\frac{\operatorname{Sr} g_{1}}{h_{1}^{2}+\mathrm{Sc} \gamma h_{1}}, \quad E_{10}=-\frac{\mathrm{Sr} g_{3}}{h_{1}^{2}+\mathrm{Sc} \gamma h_{1}}, \\
& E_{9}=-\frac{E_{10}\left(1+2 h_{1}\right)}{h_{1}^{2}+\mathrm{Sc} \gamma h_{1}}, \quad E_{12}=-\frac{\mathrm{Sr} g_{4}}{h_{2}^{2}-\mathrm{Sc} \gamma h_{2}}, \\
& E_{15}=-\frac{\operatorname{Srg}}{\left(h_{1}-h_{2}\right)^{2}+\operatorname{Sc} \gamma\left(h_{1}-h_{2}\right)}, \\
& E_{13}=-\frac{\operatorname{Sr} g_{5}}{4 h_{1}^{2}+2 S c \gamma h_{1}}, \quad E_{14}=-\frac{\operatorname{Srg} 6}{4 h_{2}^{2}-2 S c \gamma h_{2}}, \\
& H_{3}=\frac{-\mathrm{Gc} E_{1}}{\gamma}, \quad H_{4}=-\frac{\left(\mathrm{Gr} A+\mathrm{Gc} E_{1}\right)}{h_{1}^{2}+\gamma h_{1}}, \\
& H_{5}=-\frac{\left(\mathrm{Gr} B+\mathrm{Gc} E_{4}\right)}{h_{2}^{2}-\gamma h_{2}}, \\
& E_{5}=-E_{6}-E_{7}-E_{8}-E_{9}-E_{11}-E_{13}-E_{14}-E_{15} \text {, } \\
& E_{6}=\frac{\left(E_{7}+E_{8}+E_{9}+E_{11}+E_{13}+E_{14}+E_{15}\right)}{\left(e^{-S c \gamma}-1\right)} \\
& -\frac{\left(E_{7}+E_{9}+E_{10}\right) e^{h_{1}}}{\left(e^{-S c \gamma}-1\right)}-\frac{\left(E_{8}+E_{11}+E_{12}\right) e^{-h_{2}}}{\left(e^{-S c \gamma}-1\right)} \\
& -\frac{\left(E_{13} e^{2 h_{1}}+E_{14} e^{-2 h_{2}}+E_{15} e^{h_{1}-h_{2}}\right)}{\left(e^{-S c \gamma}-1\right)}, \\
& H_{6}=-\frac{\mathrm{GcE}}{\mathrm{Sc}^{2} \gamma^{2}-\mathrm{Sc} \gamma^{2}}, \quad H_{1}=-H_{2}-H_{4}-H_{5}-H_{6} \text {, } \\
& H_{9}=-\frac{\left(\mathrm{Gr} D_{3}+\mathrm{Gc} E_{5}\right)}{\gamma}
\end{aligned}
$$

$$
\begin{aligned}
& H_{10}=-\frac{\left(\mathrm{Gr} D_{1}+\mathrm{Gc} E_{7}+\mathrm{Gc} E_{9}\right)}{h_{1}^{2}+\gamma h_{1}}, \\
& H_{2}=\frac{\left(H_{4}+H_{5}+H_{6}-H_{3}\right)}{\left(e^{-\gamma}-1\right)}-\frac{H_{4} e^{h_{1}}+H_{5} e^{-h_{2}}+H_{6} e^{-\mathrm{Sc} \gamma}}{\left(e^{-\gamma}-1\right)} \text {, } \\
& H_{11}=-\frac{\left(\mathrm{Gr} D_{2}+\mathrm{Gc} E_{8}+\mathrm{Gc} E_{11}\right)}{h_{2}^{2}-\gamma h_{2}} \\
& H_{13}=-\frac{\left(\mathrm{Gr} D_{4}+\mathrm{Gc} E_{10}\right)}{h_{1}^{2}+\gamma h_{1}}, \quad H_{12}=-\frac{H_{13}\left(2 h_{1}+\gamma\right)}{h_{1}^{2}+\gamma h_{1}}, \\
& H_{15}=-\frac{\left(\mathrm{GrD}_{5}+\mathrm{Gc} E_{12}\right)}{h_{2}^{2}-\gamma h_{2}}, \quad H_{10}=-\frac{H_{15}\left(\gamma-2 h_{2}\right)}{h_{2}^{2}-\gamma h_{2}}, \\
& H_{16}=-\frac{\left(\mathrm{Gr} D_{6}+\mathrm{Gc} E_{13}\right)}{4 h_{1}^{2}+2 \gamma h_{1}}, \quad H_{17}=-\frac{\left(\mathrm{Gr} D_{8}+\mathrm{Gc} E_{14}\right)}{4 h_{2}^{2}-2 \gamma h_{2}} \\
& H_{18}=-\frac{\left(G r D_{7}+\mathrm{Gc} E_{15}\right)}{\left(h_{1}-h_{2}\right)^{2}+\gamma\left(h_{1}-h_{2}\right)}, \\
& H_{7}=-H_{8}-H_{10}-H_{11}-H_{12}-H_{14}-H_{16}-H_{17}-H_{18} \text {, } \\
& H_{8}=\frac{\left(H_{10}+H_{11}+H_{12}+H_{14}+H_{16}+H_{17}+H_{18}-H_{9}\right)}{\left(e^{-\gamma}-1\right)} \\
& -\frac{\left(H_{10}+H_{12}+H_{13}\right) e^{h_{1}}}{\left(e^{-\gamma}-1\right)}-\frac{\left(H_{11}+H_{14}+H_{15}\right) e^{-h_{2}}}{\left(e^{-\mathrm{Sc} \gamma}-1\right)} \\
& -\frac{\left(H_{16} e^{2 h_{1}}+H_{17} e^{-2 h_{2}}+H_{18} e^{h_{1}-h_{2}}\right)}{\left(e^{-\gamma}-1\right)} .
\end{aligned}
$$

\section{Nomenclature}

g: Acceleration due to gravity

Pr: Prandtl number

$H$ : Dimensionless gap between the plates

$t^{\prime}$ : Dimensional time

$t$ : Dimensionless time

$T^{\prime}$ : Dimensional temperature of the fluid

$T_{0}^{\prime}$ : Initial temperature of the fluid and plates

$C^{\prime}$ : Dimensional concentration of the fluid

$C_{0}^{\prime}$ : Initial concentration of the fluid and plates

$u^{\prime}$ : Dimensional velocity of the fluid

$u$ : Dimensionless velocity of the fluid

$y^{\prime}$ : Dimensional coordinate perpendicular to the plate

$y$ : Dimensionless coordinate perpendicular to the plate

$x^{\prime}$ : Dimensional coordinate parallel to the plate

$C_{p}$ : Specific heat of the fluid at constant pressure

$C_{0}^{*}$ : Initial concentration of the reactant species

$Q_{0}$ : Dimensional heat generating/absorbing parameter

$D_{m}$ : Coefficient of mass diffusivity

$T_{m}$ : Mean fluid temperature

$k_{T}$ : Thermal diffusion ratio

$k_{0}$ : Thermal conductivity of the fluid 


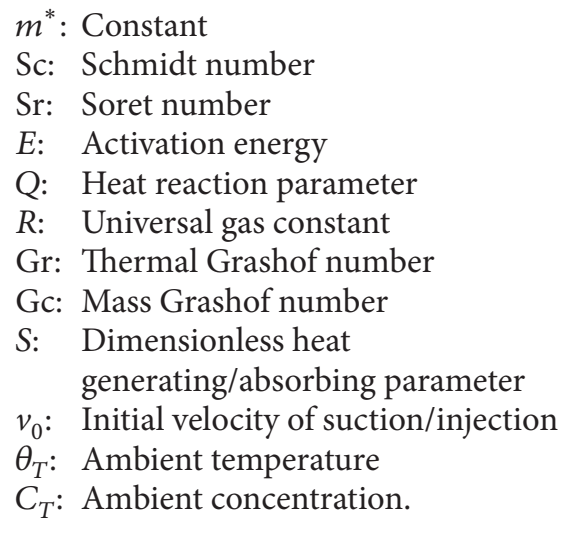

Greek Letters

$\rho$ : Density of the fluid

$\beta$ : Volumetric coefficient of thermal expansion

$\theta$ : Dimensionless temperature

$\lambda$ : Frank-Kamenetskii parameter

$\nu$ : Kinematic viscosity

$\varepsilon$ : Activation energy parameter

$\delta$ : Dimensionless variable thermal conductivity

$\gamma$ : Dimensionless velocity of suction/injection.

Subscript

$\omega$ : Wall condition.

\section{Conflict of Interests}

The authors declare that there is no conflict of interests regarding the publication of this paper.

\section{Acknowledgment}

The author M. M. Hamza is thankful to Usmanu Danfodiyo University, Sokoto, Nigeria, for financial assistance.

\section{References}

[1] B. J. Minto, D. B. Ingham, and I. Pop, "Free convection driven by an exothermic reaction on a vertical surface embedded in porous media," International Journal of Heat and Mass Transfer, vol. 41, no. 1, pp. 11-23, 1998.

[2] A. N. Campbell, S. S. S. Cardoso, and A. N. Hayhurst, "A comparison of measured temperatures with those calculated numerically and analytically for an exothermic chemical reaction inside a spherical batch reactor with natural convection," Chemical Engineering Science, vol. 62, no. 11, pp. 3068-3082, 2007.

[3] B. K. Jha, A. K. Samaila, and A. O. Ajibade, "Transient freeconvective flow of reactive viscous fluid in a vertical channel," International Communications in Heat and Mass Transfer, vol. 38, no. 5, pp. 633-637, 2011.

[4] B. K. Jha, A. K. Samaila, and A. O. Ajibade, "Transient freeconvective flow of reactive viscous fluid in vertical tube,"
Mathematical and Computer Modelling, vol. 54, no. 11-12, pp. 2880-2888, 2011.

[5] B. K. Jha, A. K. Samaila, and A. O. Ajibade, "Unsteady/steady natural convection flow of reactive viscous fluid in a vertical annulus," International Journal of Fluid Mechanics Research, vol. 39, no. 4, pp. 301-311, 2012.

[6] B. K. Jha, A. K. Samaila, and A. O. Ajibade, "Unsteady natural convection Couette flow of a reactive viscous fluid in a vertical channel," Computational Mathematics and Modeling, vol. 24, no. 3, pp. 432-442, 2013.

[7] B. K. Jha and A. O. Ajibade, "Free convective flow of heat generating/absorbing fluid between vertical porous plates with periodic heat input," International Communications in Heat and Mass Transfer, vol. 36, no. 6, pp. 624-631, 2009.

[8] K. Vajravelu, "Natural convection at a heated semiinfinite vertical plate with temperature dependent heat sources or sinks," Indian Academy of Sciences, vol. 88, no. 4, pp. 369-376, 1979.

[9] J. C. Crepeau and R. Clarksean, "Similarity solutions of natural convection with internal heat generation," Journal of Heat Transfer, vol. 119, no. 1, pp. 183-185, 1997.

[10] A. Postelnicu, "Influence of a magnetic field on heat and mass transfer by natural convection from vertical surfaces in porous media considering Soret and Dufour effects," International Journal of Heat and Mass Transfer, vol. 47, no. 6-7, pp. 1467-1472, 2004.

[11] N. G. Kafoussias and E. W. Williams, "Thermal-diffusion and diffusion-thermo effects on mixed free-forced convective and mass transfer boundary layer flow with temperature dependent viscosity," International Journal of Engineering Science, vol. 33, no. 9, pp. 1369-1384, 1995.

[12] Z. Dursunkaya and W. M. Worek, "Diffusion-thermo and thermal-diffusion effects in transient and steady natural convection from a vertical surface," International Journal of Heat and Mass Transfer, vol. 35, no. 8, pp. 2060-2065, 1992.

[13] E. Osalusi, J. Side, and R. Harris, "Thermal-diffusion and diffusion-thermo effects on combined heat and mass transfer of a steady MHD convective and slip flow due to a rotating disk with viscous dissipation and Ohmic heating," International Communications in Heat and Mass Transfer, vol. 35, no. 8, pp. 908-915, 2008

[14] R. Tsai and J. S. Huang, "Numerical study of Soret and Dufour effects on heat and mass transfer from natural convection flow over a vertical porous medium with variable wall heat fluxes," Computational Materials Science, vol. 47, no. 1, pp. 23-30, 2009.

[15] M. Turkyilmazoglu and I. Pop, "Soret and heat source effects on the unsteady radiative MHD free convection flow from an impulsively started infinite vertical plate," International Journal of Heat and Mass Transfer, vol. 55, no. 25-26, pp. 7635-7644, 2012.

[16] E. M. E. Elbarbary and N. S. Elgazery, "Chebyshev finite difference method for the effects of variable viscosity and variable thermal conductivity on heat transfer from moving surfaces with radiation," International Journal of Thermal Sciences, vol. 43, no. 9, pp. 889-899, 2004.

[17] M. S. Abel, P. S. Datti, and N. Mahesha, "Flow and heat transfer in a power-law fluid over a stretching sheet with variable thermal conductivity and non-uniform heat source," International Journal of Heat and Mass Transfer, vol. 52, no. 1112, pp. 2902-2913, 2009. 
[18] M. Arunachalam and N. R. Rajappa, "Forced convection in liquid metals with variable thermal conductivity and capacity," Acta Mechanica, vol. 31, no. 1-2, pp. 25-31, 1978.

[19] T. C. Chiam, "Heat transfer with variable conductivity in a stagnation-point flow towards a stretching sheet," International Communications in Heat and Mass Transfer, vol. 23, no. 2, pp. 239-248, 1996.

[20] T. C. Chiam, "Heat transfer in a fluid with variable thermal conductivity over a linearly stretching sheet," Acta Mechanica, vol. 129, no. 1-2, pp. 63-72, 1998.

[21] M. S. Abel, P. G. Siddheshwar, and N. Mahesha, "Effects of thermal buoyancy and variable thermal conductivity on the MHD flow and heat transfer in a power-law fluid past a vertical stretching sheet in the presence of a non-uniform heat source," International Journal of Non-Linear Mechanics, vol. 44, no. 1, pp. 1-12, 2009.

[22] M. A. Seddeek and F. A. Salama, "The effects of temperature dependent viscosity and thermal conductivity on unsteady MHD convective heat transfer past a semi-infinite vertical porous moving plate with variable suction," Computational Materials Science, vol. 40, no. 2, pp. 186-192, 2007.

[23] A. Ishak, J. H. Merkin, R. Nazar, and I. Pop, "Mixed convection boundary layer flow over a permeable vertical surface with prescribed wall heat flux," Zeitschrift für Angewandte Mathematik und Physik, vol. 59, no. 1, pp. 100-123, 2008.

[24] A. K. Singh, "Stokes problem for a porous vertical plate with heat sinks by finite difference method," Astrophysics and Space Science, vol. 103, no. 2, pp. 241-248, 1984.

[25] M. H. Shojaefard, A. R. Noorpoor, A. Avanesians, and M. Ghaffapour, "Numerical investigation of flow control by suction and injection on a subsonic airfoil," The American Journal of Applied Sciences, vol. 20, pp. 1474-1480, 2005.

[26] F. P. Foraboschi and I. di Federico, "Heat transfer in laminar flow of non-Newtonian heat-generating fluids," International Journal of Heat and Mass Transfer, vol. 7, no. 3, pp. 315-325, 1964.

[27] O. D. Makinde and T. Chinyoka, "Numerical investigation of buoyancy effects on hydromagnetic unsteady flow through a porous channel with suction/injection," Journal of Mechanical Science and Technology, vol. 27, no. 5, pp. 1557-1568, 2013. 

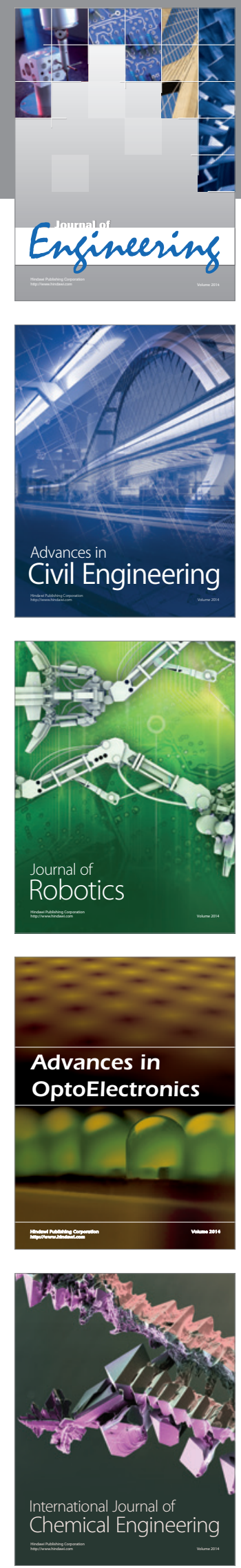

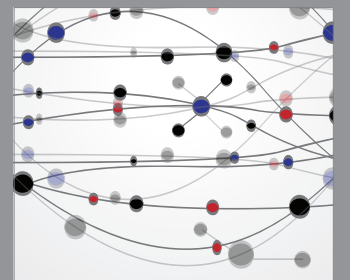

The Scientific World Journal
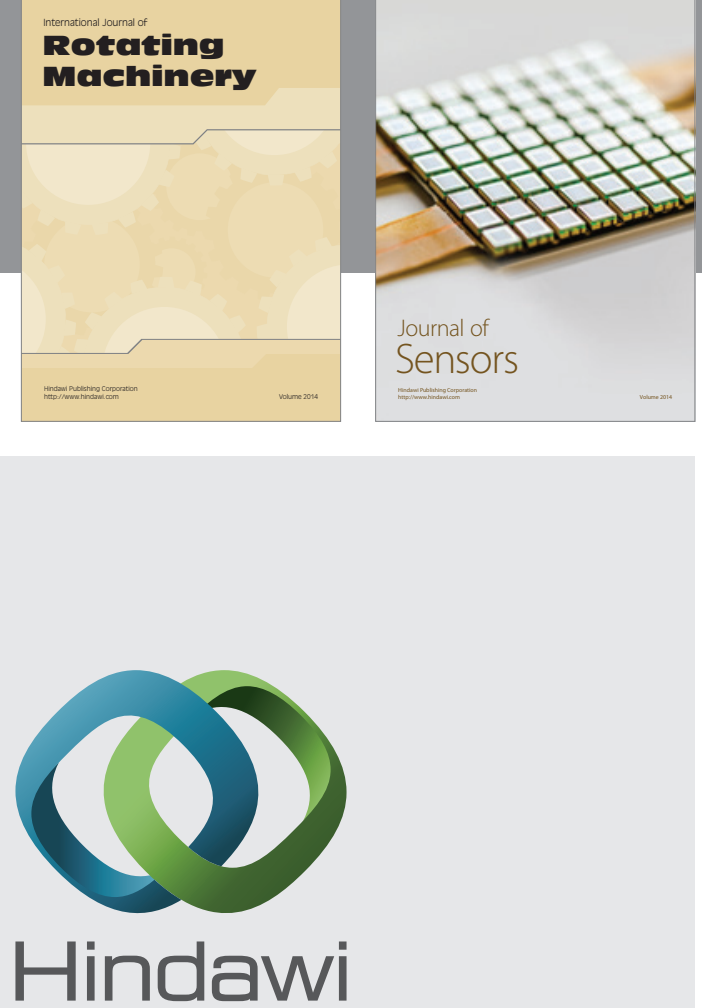

Submit your manuscripts at http://www.hindawi.com
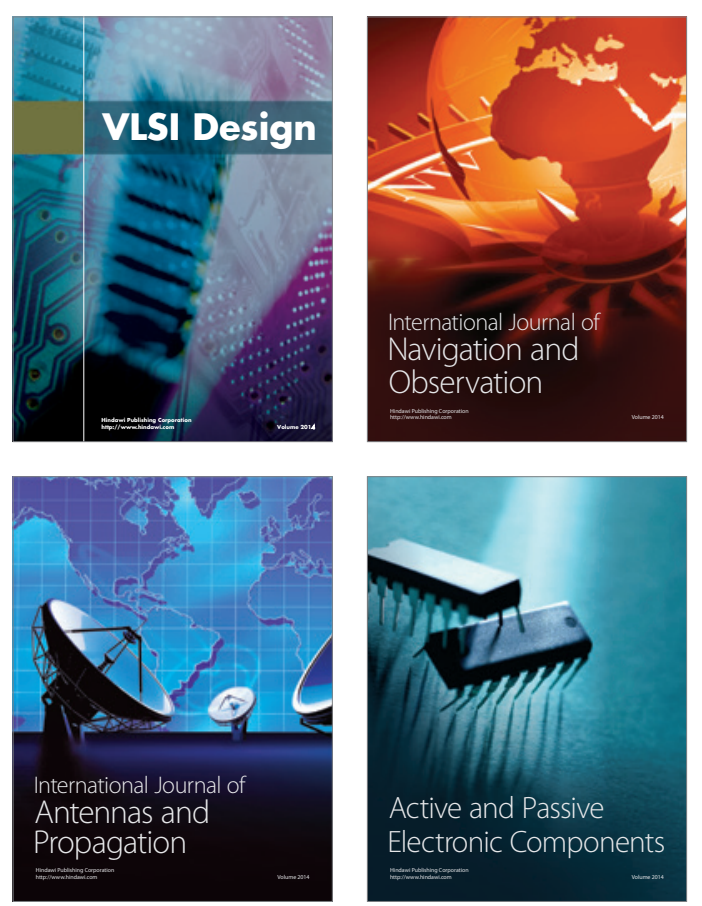
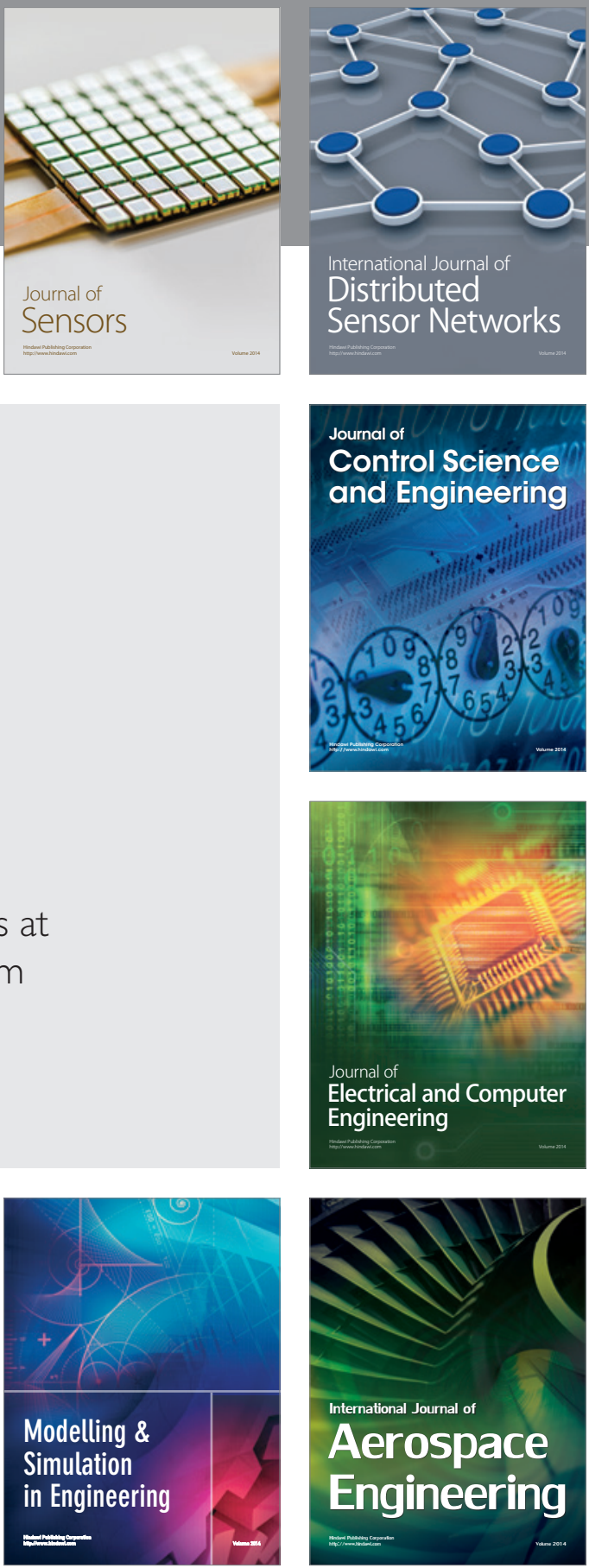

Journal of

Control Science

and Engineering
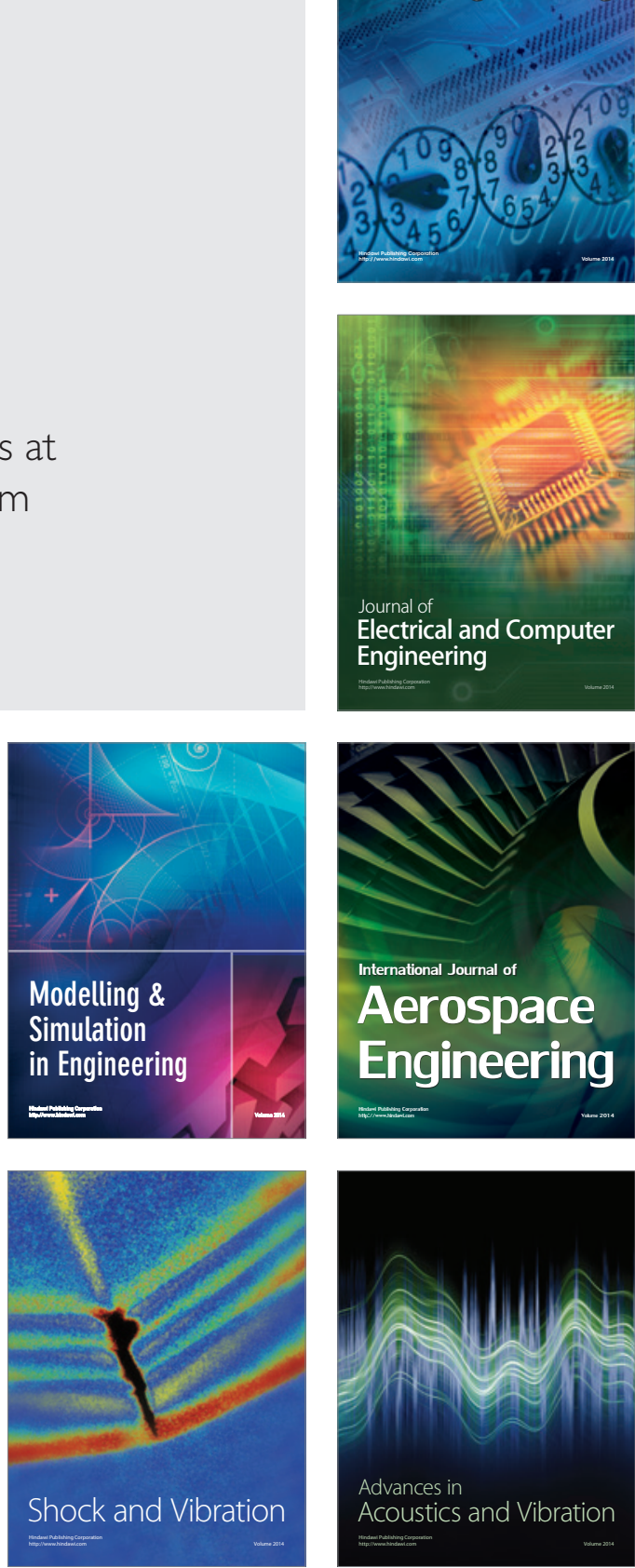